1

\title{
Hierarchical electrode design of high-capacity alloy nanomaterials for lithium-ion batteries
}

\author{
Hui Zhao, Wen Yuan, and Gao Liu* \\ Environmental Energy Technologies Division, \\ Lawrence Berkeley National Laboratory, Berkeley, California 94720, USA \\ *Tel.: +1-510-486-7207; fax: +1-510-486-7303; Email: gliu@lbl.gov (G. Liu)
}

Summary: Nanomaterials and engineering approaches to assemble these nanomaterials play critical roles in the success of next-generation of high-energy-density electrochemical energy storage devices. As an on-going effort to increase the cycle life and energy densities of lithium-ion batteries, highcapacity alloy anodes, such as silicon, tin, and their alloys have attracted considerable attention due to their high specific capacities (4200 mAh/g for Si, $994 \mathrm{mAh} / \mathrm{g}$ for Sn) compared to state-of-the-art graphite materials $(372 \mathrm{mAh} / \mathrm{g})$. These alloy materials are made into nano-size materials to achieve their full potential in capacity and life. The high-capacity material is assembled into a polymer laminate composite for a functional lithium-ion cell. However, these alloys experience a large volume change during lithiation and delithiation, which disturbs the electrode integrity, causing its mechanical failure, including delamination from the current collector and cracking of the electrode. Unlike the traditional approach to electrode architecture, new materials and approaches have been developed to assemble nanoparticles into hierarchical structures to achieve high capacity and performance. In this hierarchical approach, polymer electrode binders are a critical component to address the large volume change induced by the high specific capacity during lithiation and delithiation. We summarize the recent explosive development of polymer electrode binders for alloy nanomaterials assembly, along with the remaining challenges in this field.

Keywords: nanomaterials, nanomaterial assembly, polymer binder, silicon, lithium-ion batteries, electrochemical energy storage 


\section{Introduction}

Lithium-ion batteries (LIBs) have enabled the revolutionary development of cellphones and laptop computers, leading to accelerated global communications[1]. In a charge process, lithium ions move from the electrolyte into the anode, and the electrons move from the external circuit through the current collector into the anode, anode materials are reduced. To achieve this process, the anode laminate should be both electronic and ionic conductive. Electron transport is typically quite fast in the electrode materials (either cathode or anode), as is the ion transport in a typical liquid electrolyte, yet, the mobility of lithium ions inside the solid-state anode materials is a limiting process. To overcome this issue of lithium ion transport in the solid-state anode material, a straightforward solution is to engineer the electrode materials into small-size particles to make a short ion transport path. The active electrode materials are produced as micron-size (graphite, $\mathrm{LiCoO}_{2}$, $\mathrm{LiNi}_{1 / 3} \mathrm{Mn}_{1 / 3} \mathrm{Co}_{1 / 3} \mathrm{O}_{2}$ ) or nano-size (silicon, lithium iron phosphate) particles. Most of the lithium-ion storage materials change volume during the lithium insertion and removal process, which creates internal stress, leading to material fracture when the material dimension gets larger. Therefore, mechanical integrity and good ionic and electronic conductivities are highly desirable in the design of an electrode laminate for LIBs. Polymeric binder is a critical component in the electrode, which adhere particles together and provides a cushion for the volume changes. Nano-size conductive additives (acetylene black, AB) are added to provide electronic conductivity, enabling the electrode materials to access the electrons from the current collector. Both the porosity in the electrode and the swelling of the polymer binders by the electrolytes provide ionic conductivity. Meantime, the binders should not dissolve in the electrolyte, otherwise the electrode architecture is destroyed. The optimization of the electrode architecture[2-4] is important to achieve a satisfactory cell performance.

State-of-the-art LIBs use graphite as a negative electrode. Graphite is a crystalline, anisotropic carbonaceous material with stacked graphene layers, with $\sim 0.335 \mathrm{~nm}$ distance between each layer. Graphite has a theoretical capacity of $372 \mathrm{mAh} / \mathrm{g}$, and it undergoes a $10 \%$ volume change during the process of lithiation and delithiation[5]. This process occurs below $0.25 \mathrm{~V}$ vs. $\mathrm{Li}$, the voltage is sufficiently low to enable high-energy battery chemistry when coupled with a cathode. Alloy anodes 
such as Si and Sn have drawn extensive attention due to their high storage capacities, which are 4200 $\mathrm{mAh} / \mathrm{g}$ or $994 \mathrm{mAh} / \mathrm{g}$ for full lithiation to the $\mathrm{Li}_{22} \mathrm{Si}_{5}$ or $\mathrm{Li}_{22} \mathrm{Sn}_{5}$ phases, respectively. However, there have been no widespread applications of alloy anodes in Li-ion cells, mostly due to the large volume changes associated with Li-ion insertion and removal from the Si material. Among various efforts to address this challenge, nanostructured active materials are most promising because of their ability to alleviate mechanical strain induced by volume change. It was shown that a critical diameter for fracture of Si nanopillars is between 240 and $360 \mathrm{~nm}$ during lithiation[6]. Smaller-size Si is less likely to undergo mechanical damage. Furthermore, a reduced diffusion path for lithium ions improves ionic conductivity[7]. The improved damage tolerance and lithium-ion conductivity enable better capacity retention for the Si nano-materials. Thus, the development of Si-based nano-materials has been a major focus in the effort of applying Si anode in LIBs.

Different forms of Si nano-structures, such as nanowires[8, 9]. nanotubes[10, 11], and thin films[12] have been largely explored; yet, in the search for a commercial high-capacity anode material, the use of silicon nanoparticles is most promising. The commercial production of $\mathrm{Si}$ particles has been benefitted from their development in the semi-conductor industry, although the cost for production of nano-Si is higher compared to those of micro-size particles. Admittedly, simply using nanoparticles will not address all the problems. Active material pulverization can be largely avoided, but the drastic volume change of $\mathrm{Si}$ particles disrupts the integrity of the electrode and induces excessive side reactions, leading to fast capacity fade. Several mechanisms have been proposed to explain the capacity decay and cell failure[13], including particle isolation from the binder/conductive additive network, electrode delamination from current collectors, and continued solid electrolyte interphase (SEI)[14] growth. The electronic integrity of electrodes relies on the connections between the nonadhesive nano-size conductive additives and active materials. Even with extensive amount of conductive additive, this connection will break after extended cycles of large volume change particles[15]. The right polymer binder should provide good particle/particle cohesion to prevent particle isolation, and good laminate/current collector adhesion to prevent delamination. The intimate coating of polymer binder on the active material surface is able to modify the surface property during 
cell cycling; recent work also shows that the binder is involved in SEI formation and helps to stabilize the SEI during the drastic volume change[16, 17]. An efficient battery binder is the ultimate solution for assembling high-capacity and high-volume-change electrodes.
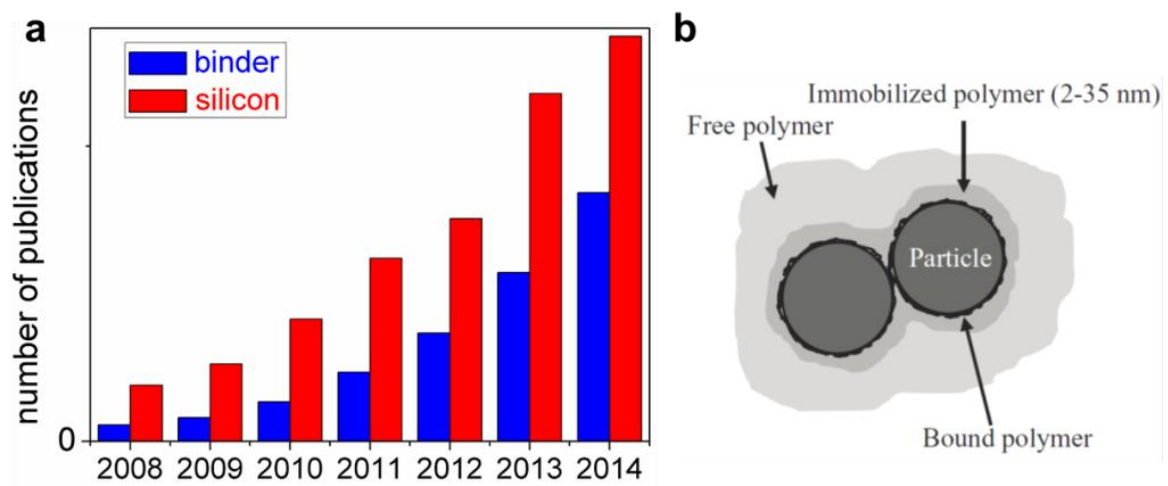

Figure 1. (a) The number of peer-reviewed publications on the development of binders or silicon anode for lithium-ion batteries as a function of the year published. Data were collected using the ISI Web of Science, with "binder" and "lithium ion battery" as search items in the "topic" box for the binder data, and "silicon" and "lithium ion battery" for the silicon data. (b) The bulk polymer differentiates into three physical states when in contact with a particle surface. Bound polymer and immobilized polymer layers on a particle surface are defined as the fixed polymer layer. The third state, free polymer, forms a conduction path where electrons are carried from the current collector throughout the electrode laminate. Copyright 2012, The Electrochemical Society.

The exploration of assembly approach of nanomaterial with new polymers as binders for LIBs has rapidly advanced in recent years, as indicated by the large number of publications from 2008 to present day (Figure 1a). The corresponding data for silicon anode is also shown for comparison. This trend shows the global significance of polymer binders and the intensive interest of scientific research in this field. To deliver the highest power, the active materials in secondary batteries for portable electronics should fill out most of the restricted volume. Thus, the amount of any other electrode laminate compositions, such as binders, conductive additives, current collectors, and separators, should be reduced to a minimum. Meantime, the lifetime and cycle numbers of the electrodes should not be sacrificed, which is critical for both electro-mobility and stationary applications.

From a theoretical point of view, polymer binders work similarly as polymer adhesives. An adhesive must satisfy two requirements to enable a good adhesion[18]:

(I) The polymer must wet the surfaces, and spread to make a contact angle of close to zero;

(II) After wetting, the polymer must harden to a cohesively strong solid. This process could 
be caused by a loss of solvent, chemical reaction, or cooling of the hot melt adhesives.

The slurry preparation should fulfill the first requirement, and loss of solvent by thermal drying is typically used to eliminate residual solvent and harden the polymer.

Several theories are used to explain the adhesion; the most common of which are physical adsorption and chemical bonding. Van der Waals forces across the interface are involved in the theory of physical adsorption, and the origin of the adsorption comes from permanent dipoles and induced dipoles. The use of polymer binders without any functional chemical groups such as polyvinylidene fluoride (PVDF) falls into this category. In contrast, other polymers, including poly(acrylic acid) (PAA), poly(vinyl alcohol) (PVA), and natural products with a high density of hydroxyl and carboxylic acid groups mainly use a chemical reaction (hydrogen bonding).

Liu et al. introduced the physics of polymer composite to understand the LIB electrode structure and performance. The surface area of the particles dominates the mixing process and polymer binder distribution. The polymer binder in the composite electrode will associate with the smaller-size conductive additive, even when the acetylene black ( $\mathrm{AB})$ is far from being the weight-dominant component of the electrode. The ratio of $\mathrm{AB}$ to binder is a critical parameter in optimizing electrode performance $[19,20]$. A high binder-to- $A B$ ratio is beneficial because it creates a more cohesive conductive carbon particle network that results in better overall local electronic, and hence, reduced charge-transfer resistance. A similar conclusion was also made by Guyomard and coworkers[21, 22]. Liu proposed a physical model in which polymer binder forms fixed nanometer-thick layers on the electrode active particle and $\mathrm{AB}$ surfaces (Figure 1b)[23]. The extra free polymer provides a stronger binder force, but excessive amount of free polymer binder tends to slow down ion transport at the interface. The active electrode ( $\mathrm{Si}, \mathrm{Sn}$, or graphite) materials typically carry functional chemical groups from the production process[24]; the polymer binder tends to chemically bond or physically adsorb to the particle surface and form the fixed polymer layer. Addition of the $\mathrm{AB}$ conductive additives, which are nanoparticles with a large surface area, competes with the active material for the polymer binder and decreases the binding strength of the electrode. 
Nanostructured alloy anode materials for LIBs have been well-covered by several recent reviews[13, 25-27]. The purpose of this review is to deliver an overview of the related progress in the assembly of nanomaterials with polymer binders in the application of high-capacity alloy-anodes in LIBs. Figure 2 shows the representative systems of polymeric binders reported in the literature. Several categories of polymer binders, including conventional synthetic polymers, natural polymers and derivatives, conductive polymers, and other novel polymer systems are summarized. Equally important as new binder development, the recent advances in the characterization of polymer binder and electrodes are also discussed. The last section briefly summarizes this review and remaining challenges.

\section{Different types of binders developed for nano-Si and $\mathrm{Sn}$ anodes}

\subsection{Conventional synthetic polymer as binders}

PVDF has been a standard polymer binder for graphite anodes and most of the metal oxide cathode materials. Lithium ions easily pass through a thin layer of swollen PVDF[28], the lowest unoccupied molecular orbital (LUMO) of PVDF is high and it is expected that this polymer is stable in an anodic environment[29].

Beaulieu et al. studied the effect of different binders for the high-capacity alloy anodes in LIBs. The 
conventional PVDF binder only delivered poor cycling performance, they argued that the poor mechanical properties of PVDF could not tolerate the huge volumetric changes of the active material particles [30]. However, after a heat-treatment above the PVDF melting point, the binder could form a continuous film on the Si surface, which enabled a significantly better cycle life[31]. A fluorinated elastomer, poly(vinylidene fluoride-tetrafluoroethylene-propylene) (PVDF-TFE-P), was selected and its mechanical properties were comprehensively investigated[32, 33]. The PVDF-TFE-P films could be extended to $100 \%$ strain either in air or ethylene carbonate (EC)/diethyl carbonate (DEC) solvents. The PVDF films, on the other hand, could not tolerate even $10 \%$ elongation before break. The better mechanical properties of PVDF-TFE-P also lead to an improved battery cycling performance when used as a binder for an a-Si ${ }_{0.64} \mathrm{Sn}_{0.36}$ alloy anode[34]. In another work, Nafion, a sulfonated polymer with a polytetrafluoro-ethylene (PTFE) backbone, was used as binder for a Si anode[35]. The prepared electrodes showed a reversible specific capacity of $800-1000 \mathrm{mAh} / \mathrm{g}$ when cycled between $0.9 \sim 0.17 \mathrm{~V}$. A capacity retention of $\sim 74 \%$ was reported after 100 cycles at a current rate of $150 \mathrm{~mA} / \mathrm{g}$.

PAA, and in some cases, its partially neutralized form, have been shown as an effective binder for $\mathrm{Si}[36,37], \mathrm{Si} /$ graphite composite[38-41] $\mathrm{SiO}[42]$, and tin alloy[43] anodes. The effect of the neutralization on the binder performance is still controversial. It was shown that the viscosity of the PAA solution increases in the neutralized form[44]. A binder film with better ionic conductivity could be formed on the active material surface to facilitate the formation of more effective SEI and to enable better capacity retention and cycling performance. In another study, Wang and co-workers used PAA and PVA as a co-binder with a 9:1 ratio. The electrode laminate was heated at $150{ }^{\circ} \mathrm{C}$ for 1 hour to induce an esterification reaction to form a cross-linked gel polymer network[45]. An areal capacity of $4.3 \mathrm{mAh} / \mathrm{cm}^{2}$ was achieved with $\mathrm{Si}$ nanoparticles, which is proposed to be due to the threedimensional (3-D) interpenetrated network of the PAA-PVA binder. After five cycles the laminate based on PAA-PVA only shows a volume variation of $4.5 \%$, this value is $19.7 \%$ for PVDF and $16.5 \%$ for CMC, which further confirmed the success of this cross-linked gel system.

\subsection{Natural polymer and derivatives as binders for a nano-Si electrode}

Before the advent of any synthetic polymers, nature had been using natural polymers as key 
components in any life form[46]. Polysaccharides, such as cellulose, alginate, and chitosan, prove to be effective polymer binders for high-capacity alloy-anodes in LIBs. The natural polymer binders rely on the functional groups, such as carboxylic acids and hydroxyl groups for adhesion. However, the downside is that there are different kinds of functional groups, and some may contribute to parasitic reactions and large irreversible capacities during cell cycling. Also, the natural products may have uncontrolled molecular weights, and the oligomer portion of the polymer will negatively influence the polymer's mechanical and binding properties. However, natural products are widely available and cheap, and the slurry preparation and lamination process are environmentally benign (in water). Both features make this family of binders promising candidates.

Three different polysaccharides (amylose, amylopectin, and glycogen) were examined as polymer binders for silicon/graphite composite electrodes[47]. Several different advantages were discovered compared to PVDF: an improved first-cycle coulombic efficiency (CE) and suppressed electrolyte decomposition, and better cycling performance and capacity retention. Amylopectin exhibited the best electrochemical performance. In another work, a natural polysaccharide binder, agarose, was used as a carbon source and polymer binder to increase the electrical conductivity of active materials[48]. The cross-linked binder was claimed to effectively cover macroporous Si particles, and a high reversible capacity $(\sim 2350 \mathrm{mAh} / \mathrm{g})$ at a fast rate $(10 \mathrm{Ah} / \mathrm{g})$ was achieved with a $\mathrm{CE}$ of $89.8 \%$. Naturally abundant gum arabic (GA), composed of polysaccharides and glycoproteins, was applied as a dual-functional binder[49]. Hydroxyl groups of the polysaccharide in GA ensure the strong bonding to $\mathrm{Si}$, while the long chain glycoproteins provides further mechanical tolerance to the dramatic volume expansion by Si nanoparticles. A specific capacity of $2000 \mathrm{mAh} / \mathrm{g}$ at $1 \mathrm{C}$ rate and $1000 \mathrm{mAh} / \mathrm{g}$ at $2 \mathrm{C}$ rate were achieved for above 500 cycles.

Carboxymethyl cellulose (CMC), synthesized by a reaction between cellulose and chloroacetic acid, is a stiff polymer with a glass transition temperature of around $230{ }^{\circ} \mathrm{C}[50]$. It was used as a thickener for a styrene-butadiene-rubber (SBR)/water dispersion-based slurry, since SBR only dispersed as small particles in water and the viscosity of the slurry needs to be improved by the dissolved CMC[51]. Liu et al. used SBR/CMC co-binder for a silicon-based anode, and a reversible 
capacity of $600 \mathrm{mAh} / \mathrm{g}$ for over 50 cycles was demonstrated[52]. Buqa et al. used SBR/CMC together as a binder for graphite/nano-silicon anode, and it showed an apparent advantage compared to PVDF. Buqa et al. revealed that the improvement actually came from CMC[53]. Li et al. clearly pointed out that the CMC binder was the origin of the advantageous performance in the above studies; they assembled electrode laminate using CMC and a commercial Si powder, which exhibited a specific capacity of $1100 \mathrm{mAh} / \mathrm{g}$ for 70 cycles, a vastly improved cycling performance compared to the PVDFbased Si laminate[54]. Since then, CMC binder has been the "standard" choice for Si anode, due to its water solubility, relatively cheap cost and superior performance as a binder for alloy anode. The investigation of the CMC binder on alloy anode has been an on-going topic for over a decade.

Key et al. observed that after a full discharge of a lithium-silicon electrode, the open-circuit potential continued to increase even after 320 hours at room temperature, which they attributed to the reactivity of the metastable phase with the electrolyte and subsequent loss of lithium[55]. The CMC was shown to largely suppress this phenomenon, a relaxation of the open-circuit potential to $170 \mathrm{mV}$ after a full lithiation took nine days in a binder-free system, while CMC delayed this period to a month. Taking advantage of the stiff nature of the CMC binder, Wang and co-workers used a slurry spray technique to elaborate a CMC porous scaffold for $\mathrm{Si}$ anodes, and an improved cycling stability and rate performance was obtained[56]. Several research groups investigated the interaction between CMC and the surface active group on $\mathrm{Si}[57-59]$. Guyomard and co-workers[60] showed that the extended conformation of CMC in solution facilitates a networking process of the conductive additive and Si particles during the composite electrode fabrication. By tuning the $\mathrm{pH}$ of the slurry, they were able to change the neutralization degree of the acid groups on $\mathrm{CMC}$, and the favored interaction between $\mathrm{Si}$ and $\mathrm{CMC}$ could contribute to a remarkable cycle life of the nano-Si/CMC electrode. 

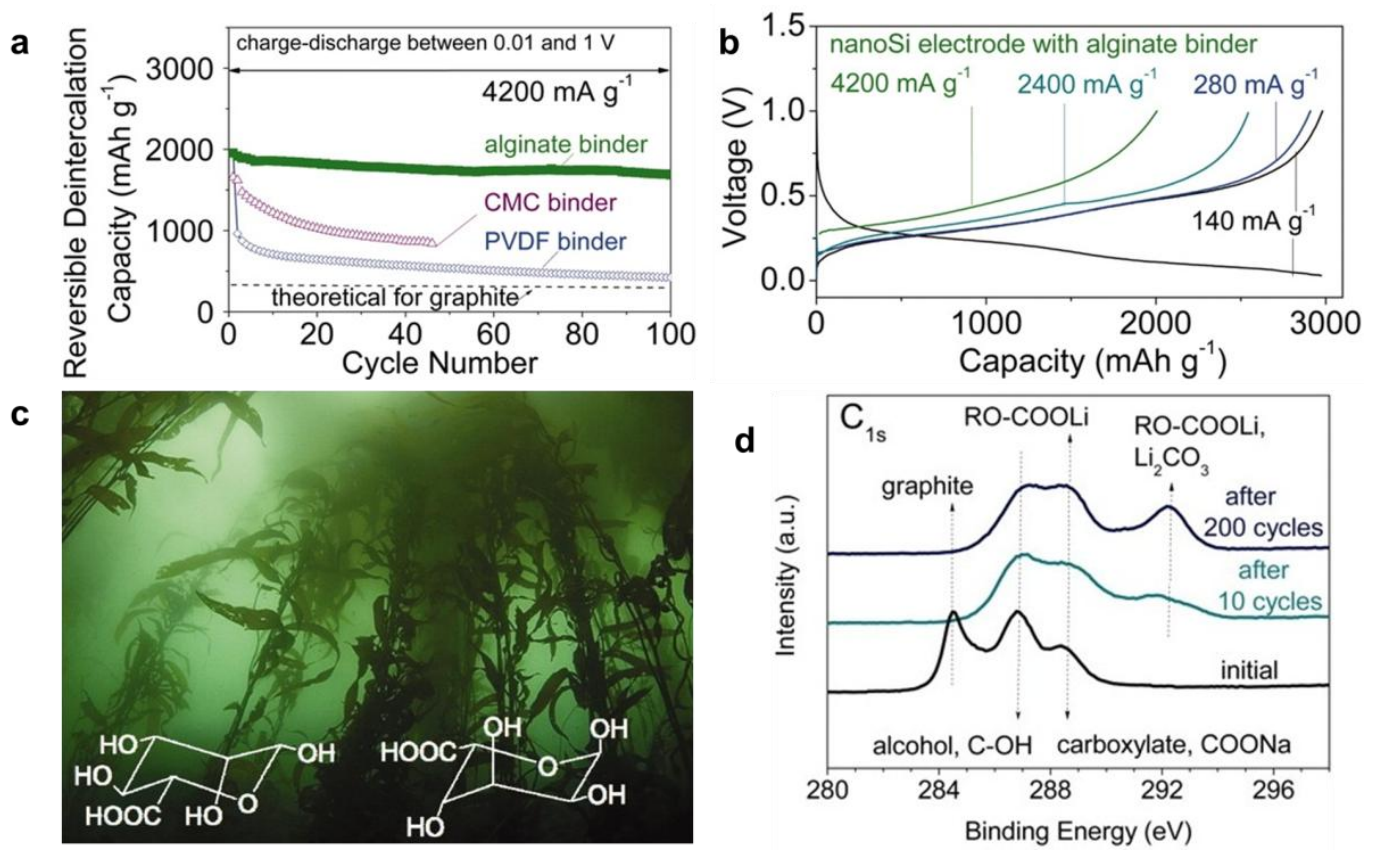

8

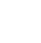

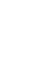

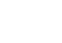

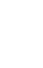

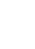

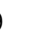

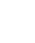

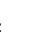

.

.

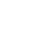

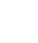

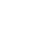

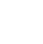

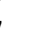

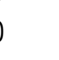
.

5

6
.

.
.

Figure 3. (a) Galvanostatic cycling performance of nano-Si electrodes with alginate, CMC, and PVDF binders at a current density of $4200 \mathrm{~mA} / \mathrm{g}$, in the voltage window of $0.01 \mathrm{~V}-1 \mathrm{~V}$. (b) Charge/discharge voltage curves of the nano-Si electrode at different current densities. (c) Giant kelp forest (Macrocystis pynfera algae) in the Pacific Ocean, with the chemical structure of mannuronic (left) and guluronic (right) acids. (d) X-ray photoelectron spectroscopy (XPS) C 1s spectra on the alginate-based Si anode before and after cycling. There are no major changes of the SEI chemistry after cycling for 10 or 200 cycles, indicating the stability of the SEI. Copyright 2011, The American Association for the Advancement of Science.

As mentioned in the section above, CMC was synthesized by functionalizing cellulose with chloroacetic acid. Since it is difficult to achieve a $100 \%$ conversion modification on a rigid polymer like CMC, it is not guaranteed that the carboxylic acid group is evenly present on every repeating unit. Alginate, a natural polysaccharide extracted from brown algae, is a copolymer of 1-4 linked $\beta$-Dmannuronic acid (M) and $\alpha$-L-guluronic acid $(\mathrm{G})$ residues (Figure 3c)[16]. Carboxylic acid groups are naturally present and averagely distributed in the polymer backbone. Electrode laminate based on $\mathrm{Si}$ nanoparticles and this natural binder exhibits a specific capacity of around $2000 \mathrm{mAh} / \mathrm{g}$ at a $1 \mathrm{C}$ rate (Figure $3 \mathrm{a}$ and $3 \mathrm{~b}$ ). Of a special notice is the effect of this binder on the SEI stability of the Si anode, as shown in the C 1s X-ray photoelectron spectroscopy (XPS) data in Figure 3d. There is basically no obvious change of the SEI chemistry from $10^{\text {th }}$ to $200^{\text {th }}$ cycle, indicating good SEI stability. It is proposed that this excellent SEI stability provided by alginate is from the interaction between the 
electrolyte and the functional groups on alginate-a similar effect as in CMC/anode material systems $[58,61]$.

A carboxymethyl chitosan was explored as a water-soluble binder for a silicon/graphite composite electrode[62]. Fourier transform infrared spectroscopy (FTIR) spectra confirmed the bonding between the binder and the Si nanoparticle surface, and this new binder enabled better cycling performance of Si/graphite electrodes than $\mathrm{CMC}$ or alginate. Both CMC and PAA were used as co-binders and treated at a high temperature $\left(150{ }^{\circ} \mathrm{C}\right)$ to trigger esterification between the carboxylic acid groups on CMC and the hydroxyl groups on PAA[63]. A reversible capacity of over $2000 \mathrm{mAh} / \mathrm{g}$ after 100 cycles was obtained at room temperature, a superior capacity of $1500 \mathrm{mAh} / \mathrm{g}$ was achieved with a high current density of $7 \mathrm{C}(30 \mathrm{~A} / \mathrm{g})$ at $60{ }^{\circ} \mathrm{C}$. Elimination of the active groups and enhancing the mechanical property of the cross-linked bi-binder structure led to cell performance improvement. Gum Arabic (GA) was also combined with PAA to induce esterification reaction and establish a flexible network, which provides reinforced mechanical strength and enhanced coherent strength. It was observed that micro-size pores were generated during esterification reaction, which relieves the stress and blocks the formation and propagation of cracks, leading to a high areal capacity Si anode (above $2 \mathrm{mAh} / \mathrm{cm}^{2}$ at $0.2 \mathrm{C}$ rate)[64].

The exceptional adhesion property of a mussel to adhere on a wet surface comes from a special structure moiety-catechol[65, 66]. Ryou et al. incorporated catechol into alginate (Alg-C) and PAA (PAA-C), and the modified binder showed much improved binding and cycling performance compared to alginate and PAA[67]. The Alg-C-based Si electrode barely showed any capacity fade at a $3 \mathrm{C}$ rate compared to that at a $\mathrm{C} / 10$ rate. A specific capacity of around $2500 \mathrm{mAh} / \mathrm{g}-\mathrm{Si}$ was obtained for both rates, with 3\% fluoroethylene carbonate (FEC) additive in the electrolyte, at a loading of 0.2 $0.3 \mathrm{mg} / \mathrm{cm}^{2}$. Park et al. incorporated a photoreactive benzophenone group into PAA (PAA-BP) as a binder for Si-based anodes[68]. Nanoindentation and swelling measurements indicate enhanced mechanical properties of the photo-cross-linked PAA-BP binder, which limited the volume change marginally (38\%) after full lithiation.

Jeong et al. treated $\beta$-cyclodextrin with epichlorohydrin under strong basic conditions to form a 
hyperbranched $\beta$-cyclodextrin polymer $(\beta$-CDp)[69]. Multidimensional hydrogen-bonding offers robust interaction with the Si particles; a self-healing effect was proposed which could recover the multidimensional binder network even if the Si nanoparticles were to lose their original contact with the binder during cycling. With a Si active material loading of $40 \mathrm{wt} \%$, the lithium-ion half cell with $\beta$-CDp delivered a reversible capacity of around $1700 \mathrm{mAh} / \mathrm{g}$ at a $1 \mathrm{C}(4200 \mathrm{~mA} / \mathrm{g})$ rate, while alginate only exhibited a capacity of around $600 \mathrm{mAh} / \mathrm{g}$.

\subsection{Conductive polymer binders for nano-Si, Sn and sodium-ion battery}

Conductive polymers are a category of functional polymers that have a delocalized $\pi$-system backbone. The highly conjugated backbone structure has reversible chemical, electrochemical, and physical properties controlled by a doping/de-doping process[70]. A novel concept was demonstrated that combined binding and conducting properties in the binder molecules (Figure 4), e.g., a conductive polymer binder[71]. Poly(9,9-dioctylfluorene-co-fluorenone-co-methylbenzoic ester) (PFM) has a polyfluorene-based structure, which is cathodically (reduction) doped in the Si electrode environment to achieve electrical conductivity[72]. Adhesion groups (benzoate) are incorporated into the polymer binder to improve the integrity of the composite electrode. A PFM/nano-Si electrode without any conductive additives was fabricated. The electrode demonstrated over 650 cycles between $1 \mathrm{~V}$ and $0.01 \mathrm{~V}$ at the $2500 \mathrm{mAh} / \mathrm{g}$-Si with only $20 \%$ capacity fade. The conductive polymer binders have opened a new paradigm of electrode design for Si materials, providing molecular-level electrical interaction between the electrode matrix and active materials and accommodating the volume expansion of high-capacity alloy materials. 


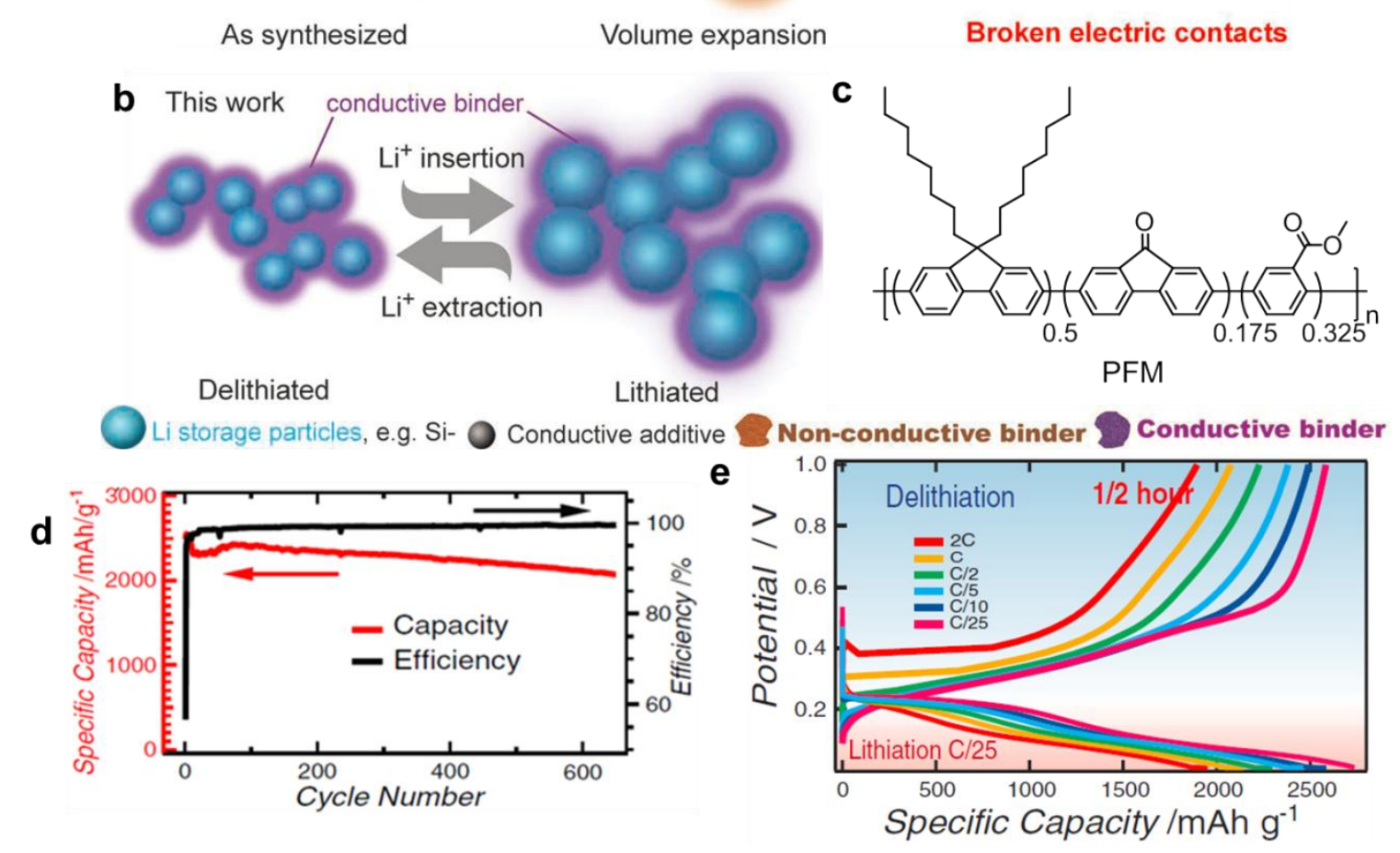

Figure 4. Schematics of the technical approaches to address the volume change issue in battery materials. (a) Traditional approaches use $\mathrm{AB}$ as conductive additive and PVDF polymer as the binder. (b) A conductive polymer with dual functionality, as a conductor and binder, could maintain the electrical and mechanical integrity of the electrode during the battery cycles. (c) The molecular structure of the PFM conductive polymer, with carbonyl and methyl benzoic ester, for tailoring the conduction band and for improving the mechanical binding force, respectively. (d) Cycling performance of Si/PFM electrode between a cycling voltage of $0.01 \mathrm{~V}$ and $1 \mathrm{~V}$ for over 650 cycles at $\mathrm{C} / 10$ rate. (e) Electrode rate performance. Copyright 2011 Wiley-VCH.

As experimentally verified using synchrotron soft X-ray absorption spectroscopy (XAS) results and the density functional theory (DFT) calculations, the optimized electronic structure of PFM enables an in situ electron doping of the polymers under the Li-ion chemistry. The electronic conductivity of the PFM polymer reaches $4.9 * 10^{-6} \mathrm{~S} / \mathrm{cm}$ after the first lithiation cycle. The conductivity is much lower than that of $\mathrm{AB}$ conductive additive particles because the doped electrons are somewhat localized as indicated by the isosurfaces[71]. The specific conductivity of $\mathrm{AB}$ is typically in the range from $0.1 \sim 100 \mathrm{~S} / \mathrm{cm}$, but both the particles and particle-to-particle connections for electron transport are 
rigid. The $\mathrm{AB}$ composite tends to lose electronic conductivity due to volume change of the $\mathrm{Si}$ materials. Therefore, such moderate improvement on conductivity of the conductive polymer binder over that of the nonconductive polymer binder has led to tremendous improvement of the Si electrode performance, as shown in Figure 4d and e.
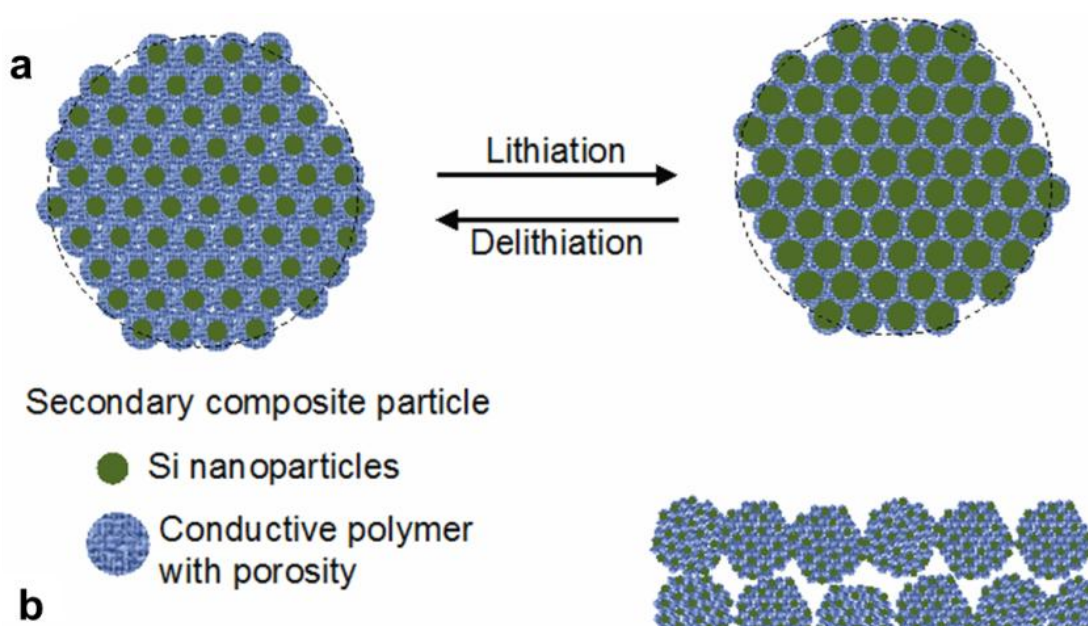

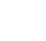

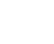

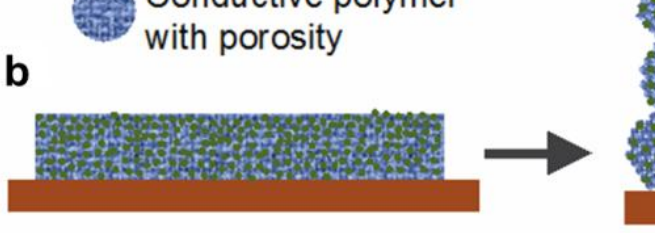

Plainer electrode

Cu current collector
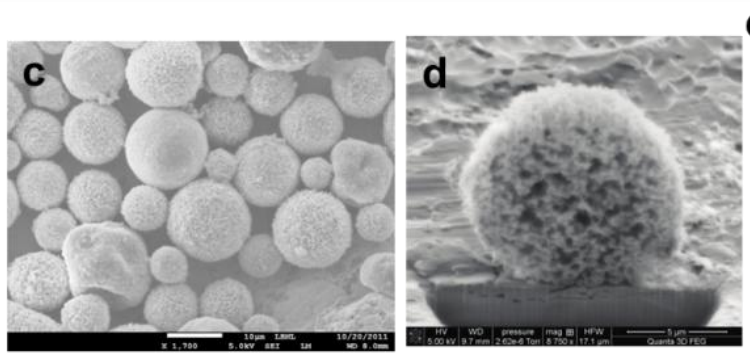

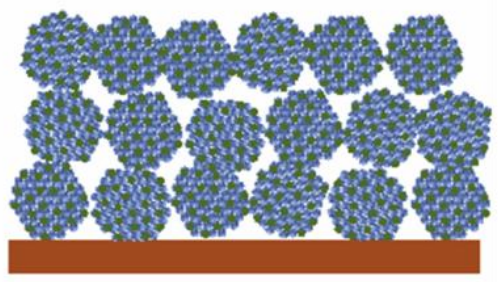

Secondary composite particles electrode

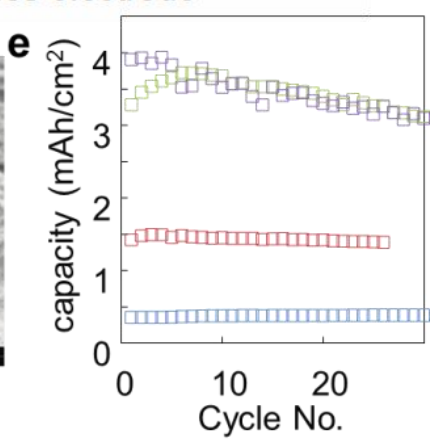

Figure 5. Schematic of the working principles of a hierarchal electrode design. (a) Secondary composite particles have a stable dimension during Si lithiation and delithiation. The dotted lines are for visual guidance. (b) A planar electrode made with a conductive polymer binder and Si nanoparticles vs. an electrode made with secondary composite particles. There are larger pores between the secondary composite particles. (c) Scanning electron microscope (SEM) images of the $\mathrm{Si} /$ conductive polymer secondary composite particles. (d) The cross-section morphology of a single secondary particle. (e) Cycling performance of the hierarchical electrode made with a Si/conductive polymer binder composite secondary particles, indicating a significantly improved loading and cycling stability. Copyright 2013, The Electrochemical Society.

Besides the electron transport issue, lithium-ion transport decay is another major issue within the Si-based electrode[73]. The mechanical movement of the electrode due to $\mathrm{Si}$ volume change 
during cycling alters the original structure of the Si electrode. Both experiments and modeling have confirmed that Si content needs to be below $40 \%$ (volume, not considering porosity) in a composite electrode for a workable Si electrode[74]. In a conventional Si composite, the $\mathrm{AB}$ and binder tend to be pushed upward to the seal of the surface porosity and reduce the lithium-ion diffusion rate. Therefore, a thinner electrode performs much better than a thicker electrode, which decays very rapidly during cycling. This reduced lithium ion diffusion limits the critical dimension of the electrode thickness to be around $10 \mu \mathrm{m}$ based on our experiments of different thickness of the Si/PFM laminates. Si/PFM spherical particles with an average diameter of $10 \mu \mathrm{m}$ were generated via a spray/precipitation method[75]. The hierarchical designed electrode with these secondary Si/PFM particles could achieve an areal capacity as high as $4 \mathrm{mAh} / \mathrm{cm}^{2}$ with significantly better capacity retention and rate performance compared to the regular Si/PFM electrode system, as shown in Figure 5. 
Figure 6. Schematics of the lithiation and delithiation process of composite anode electrodes using micrometer-size Si particles as active lithium-ion storage materials. (a) When $\mathrm{AB}$ is used, the absolute volume expansion of any individual particles is in the cube micrometer range. This large volume change has pushed the binders and $\mathrm{AB}$ composite to expand during the charge. During discharge, the $\mathrm{AB} / \mathrm{binder}$ composite does not fully recover, leaving gaps between the $\mathrm{Si}$ active materials and the AB/binder conductive matrix. (b) When Si nanoparticles are used as an additive along with a conductive polymer binder during the charge process, the Si nanoparticles and micrometer-size Si tend to fuse to form a network structure to cushion the volume expansion. The physical connections between the micrometer-size Si particles and the conductive network are preserved during the discharge process. Electrochemical performance of composite electrodes (c) m-Si/AB/PFM and (d) m-Si/n-Si/PFM. Copyright 2013, American Chemical Society.

To address the significant challenges associated with large volume change of micrometer-size $\mathrm{Si}$ (m-Si) particles as high-capacity anode materials for lithium-ion batteries, Si nanoparticles (n-Si) were used as a structural and conductive additive, with micrometer-size $\mathrm{Si}$ as the main lithium-ion storage 
material[76]. This system offers three advantages over conventional pure micrometer-size silicon-, AB-, and PVDF-based electrodes (Figure 6a and b): (1) The in-situ formed n-Si and m-Si 3D network takes advantage of the high surface area of small-size n-Si, thereby significantly alleviating the huge stress created by m-Si during the lithiation and delithiation process. (2) This network works like threedimensional cross-linked advanced polymer binders, which have been shown in literature to help confine the $\mathrm{Si}$ particles in place, with higher resistance to strain-particularly nonrecoverable deformation. (3) A novel conductive polymer binder PFM can be used over the insulating PVDF to replace the nonbonding acetylene black. All three aspects play an indispensable role in this system's success. The resulting electrode showed a high specific capacity of $2500 \mathrm{mAh} / \mathrm{g}$ after 30 cycles with high initial coulombic efficiency (73\%, Figure 6d) and good rate performance during electrochemical lithiation and delithiation: between 0.01 and $1 \mathrm{~V}$ vs $\mathrm{Li} / \mathrm{Li}^{+}$.

PFM has been successfully applied to other types of high-capacity anode materials for LIBs. Silicon oxide $(\mathrm{SiO})$ has been considered to be a promising anode candidate for LIBs, with active $\mathrm{Si}$ dispersed in inactive silica as a nano-size domain. Two major obstacles have kept the SiO anode from reaching its full potential in LIBs: the excessive volume change of the micron-size $\mathrm{SiO}$ particles (compared to graphite), and the consumption of Li during the activation process (resulting in low first cycle coulombic efficiency). The PFM conductive polymer binder with a polar ester functional group is designed to adhere to the $\mathrm{SiO}_{2}$ surface. Since the $\mathrm{SiO}_{2}$ domains remain dimensionally stable in subsequent charge and discharge reactions, and are part of the stable surface of $\mathrm{SiO}$ materials, the adhesion between the functional conductive binder PFM and $\mathrm{SiO}$ materials is much more effective than in the Si system with the same functional conductive polymer binder (Figure 7a). PFM enabled the reversible cycling of $\mathrm{SiO}$ above $1000 \mathrm{mAh} / \mathrm{g}$ for over 400 cycles at a $\mathrm{C} / 10$ rate in a half cell, with active $\mathrm{SiO}$ loading as high as $98 \mathrm{wt} \%$ (Figure 7b). XPS and TOF-SIMS analysis results indicate that the strong bonding between the silicon dioxide phase and functional conductive polymer binder results in good cycling performance with a minimum amount of binder. A follow-up work disclosed that the areal capacity could reach as high as $3.5 \mathrm{mAh} / \mathrm{cm}^{2}$ by carefully engineering the electrode architecture (calendering)[77]. 


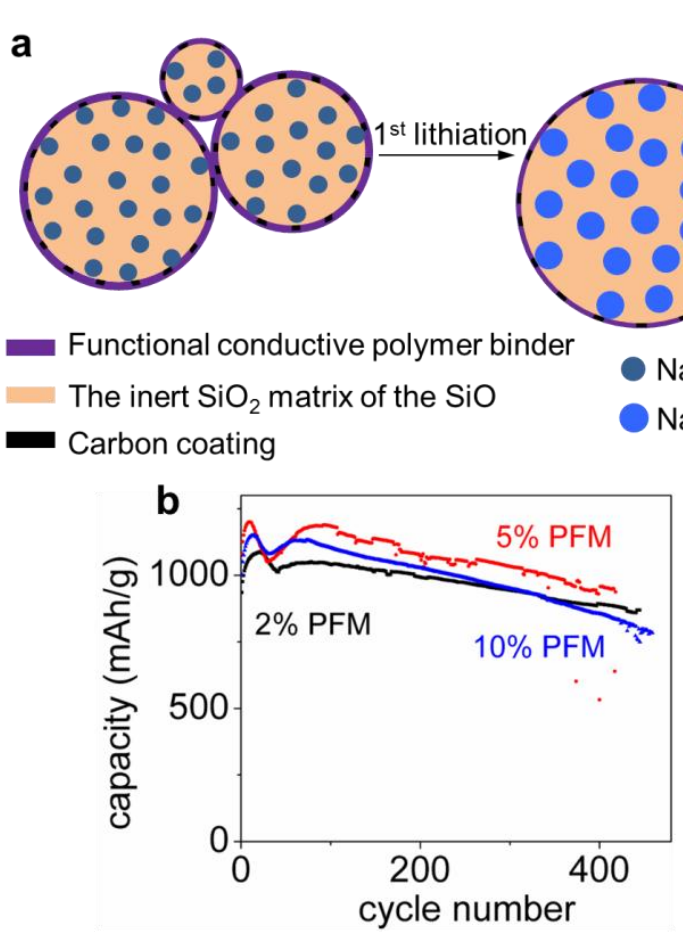

Nano Si domain

Nano lithiated Si domain

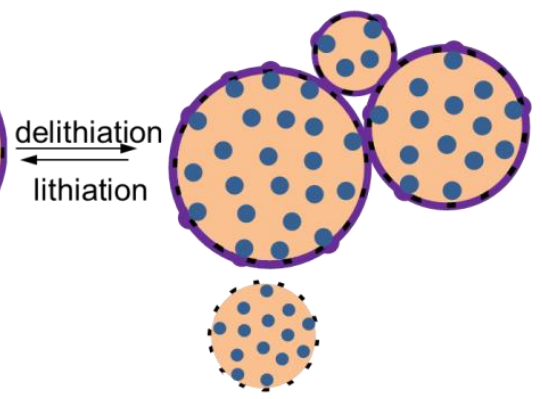

porous carbon coated $\mathrm{SiO}$
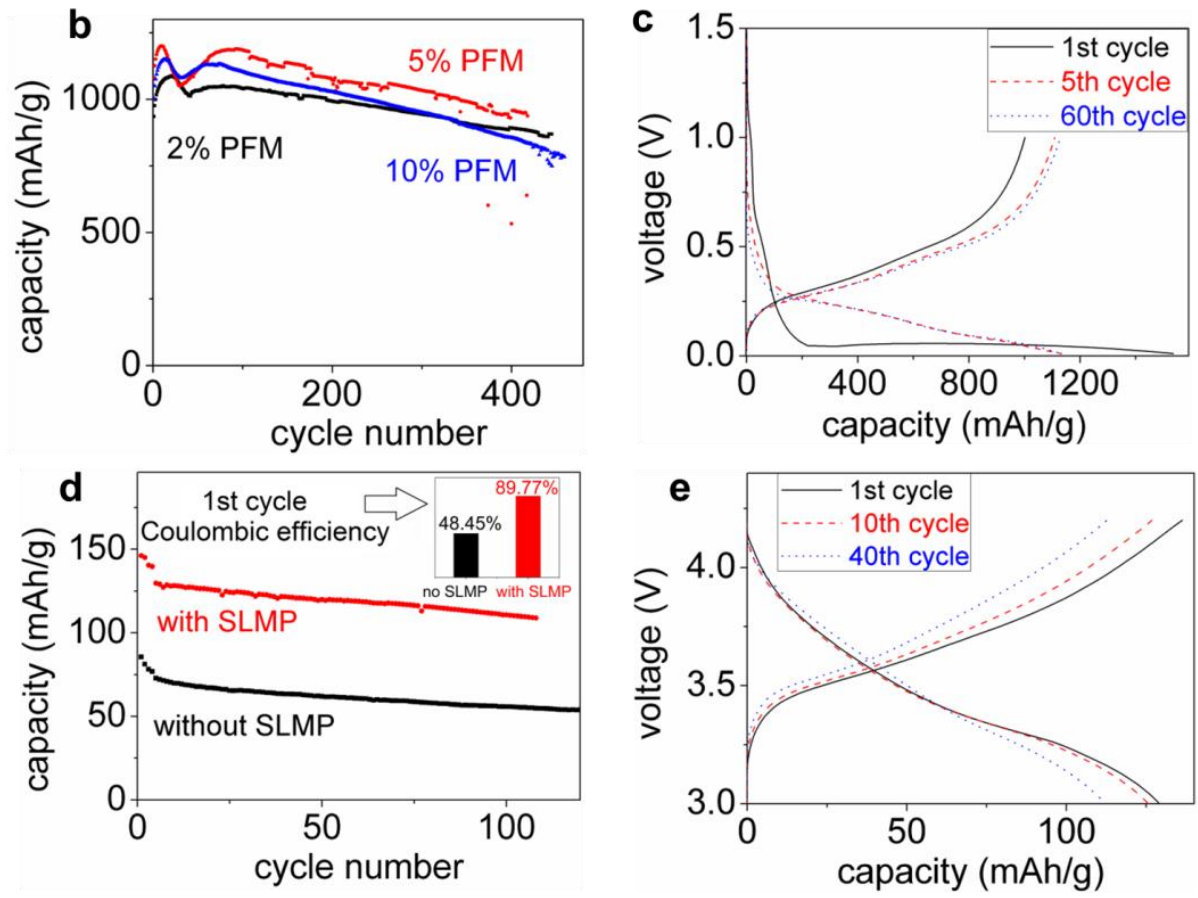

Figure 7. (a) The schematic of a low concentration of functional conductive polymer binder and $\mathrm{SiO}$ electrode. (b) Cycling performance in gravimetric capacity retention of $\mathrm{SiO}$ anodes with $2 \%, 5 \%$, and $10 \%$ by weight of PFM binder using lithium counter electrodes at a $\mathrm{C} / 10$ rate $(200 \mathrm{~mA} / \mathrm{g})$. (c) $1^{\text {st }}, 5^{\text {th }}$ and $60^{\text {th }}$ cycle potential vs. capacity curves of a $2 \%$ $\mathrm{PFM} / \mathrm{SiO}$ electrode. (d) $\mathrm{SiO} / \mathrm{NMC}$ full cell performance with or without SLMP capacity enhancement additive, C/20 for 2 cycles, $\mathrm{C} / 10$ for 2 cycles and then C/3. (e) $1^{\text {st }}, 10^{\text {th }}$ and $40^{\text {th }}$ cycle voltage curves of the SiO/NMC full cell with stabilized lithium metal powder (SLMP). Copyright 2014, American Chemical Society.

Another obstacle with the application of $\mathrm{SiO}$ materials in LIBs is that the first cycle $\mathrm{CE}$ of $\mathrm{SiO}$ is low (50\% 70\%), so both SEI formation and interaction between lithium and silicon oxide (to form silicate) contribute to the large first-cycle irreversible capacity. This is a detrimental problem in a lithium-ion cell, since the lithium ion from the cathode will be irreversibly consumed. Stabilized lithium metal powder $(\mathrm{SLMP} \circledast)[78,79]$ is used to prelithiate the $\mathrm{SiO}$ anode and compensate for the irreversible capacity loss in the first cycle. The first cycle $\mathrm{CE}$ in the SiO/NMC full cell was improved 
from $48 \%$ to $\sim 90 \%$, and an extraordinary capacity retention (>90\% after 100 cycles at $\mathrm{C} / 3$ ) was realized by this unique strategy of using both functional conductive polymer binder and SLMP prelithiation (Figure 7d). PFM was shown to improve the cycling performance of a pure Sn nanoparticle at $520 \mathrm{mAh} / \mathrm{g}$-Sn reversible capacity, with only $5 \%$ of the binder in the composite electrode[80]. Because of the high Sn loading in the laminate, the reversible capacity of the electrode could reach close to $500 \mathrm{mAh} / \mathrm{g}$. The $\mathrm{PFM} / \mathrm{Sn}$ anode is also successfully used in sodium ion battery, which delivers $806 \mathrm{mAh} / \mathrm{g}$ at $\mathrm{C} / 50$ and $610 \mathrm{mAh} / \mathrm{g}$ at C/10, exhibiting higher specific capacity and cycling stability compared with the Sn/CMC and Sn/PVDF electrode[81].

As part of the on-going effort toward developing an ideal polymer binder design for highcapacity battery anodes, triethyleneoxide monomethylether (E in Figure 8) was incorporated into a conductive polymer to improve its polarity and enhance its electrolyte uptake capability. The challenge in designing a single-component battery binder is that modifications made to improve individual functionality must not be detrimental to one other; such impacts are circumvented by modifying only the side chains on the backbone of the polyfluorene conductive polymer.

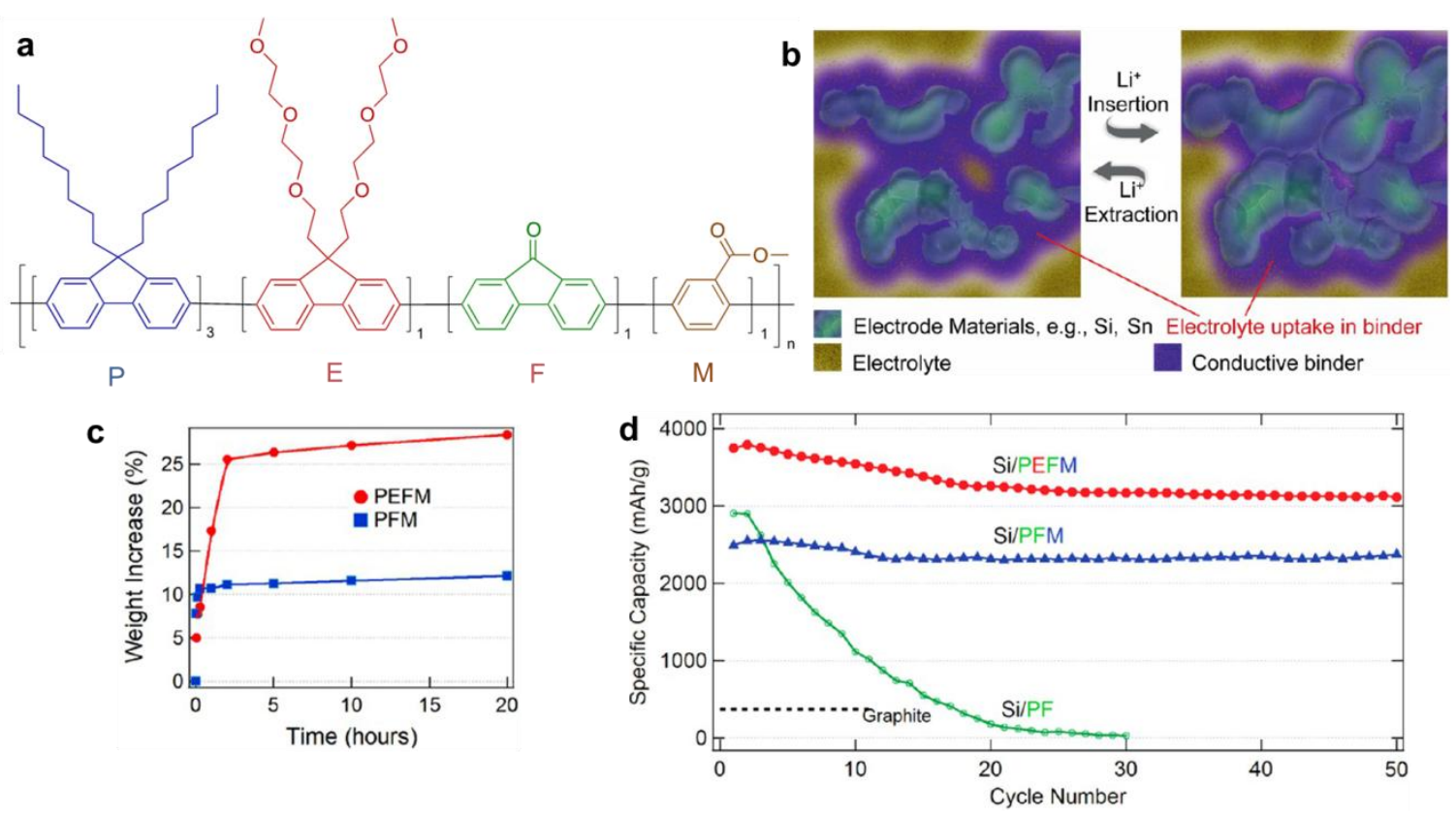

Figure 8. (a) Chemical structure of the PEFM binder. Functional groups contribute specific functionalities when the polymer is used as a binder in Li-ion batteries, $\mathrm{P}$ : polyfluorene with octyl side chains, contributes to the electronic conductivity, E: fluorenone with triethyleneoxide monomethyl ether side chains contributes to electrolyte uptake and mechanical property, F: fluorenone contributes to an optimized electronic conductivity, M: methyl benzoate ester contributes to good mechanical properties. (b) Schematic of an ideal binder system for high-capacity battery electrodes. 
(c) The swelling tests of PEFM and PFM polymer film in the $1 \mathrm{M} \mathrm{LiPF}_{6} \mathrm{EC}_{\mathrm{DEC}}(1 / 1)$ electrolyte. The electrolyte uptake in PEFM is three times higher than that in PFM and is at the same level as that for a conventional PVDF binder.

(d) Cycling performance of PFM/Si composite electrodes. PEFM enables the cycling with a full theoretical capacity of $\mathrm{Si}$ at $3750 \mathrm{mAh} / \mathrm{g}$; the volume change of $\mathrm{Si}$ at this capacity is $100 \%$ higher than that of the PFM-based binder at 2500 mAh/g. Copyright 2013, American Chemical Society.

XAS and DFT calculation indicate that incorporation of E only leads to spectroscopic difference at higher energies away from the LUMO states, but has no effect on electronic conductivity[82]. The adhesion and swelling (electrolyte intake) have been the critical properties of the binder. The enhanced polarity of the PEFM polymer leads to a three-fold electrolyte uptake (Figure 8c). The PFM conductive binder has $\sim 10 \%$ swelling in the standard EC/DEC (1/1 wt.) LiPF $_{6}$ electrolyte, while PEFM has $30 \%$ swelling $[52,83]$. A reversible capacity of $3500 \mathrm{mAh} / \mathrm{g}-\mathrm{Si}$ was demonstrated with the modified binder (Figure 8d), which has close to $100 \%$ higher volume expansion than the $\mathrm{PFM} / \mathrm{Si}$ system with a specific capacity at $2500 \mathrm{mAh} / \mathrm{g}$, but the PEFM binder effectively maintained stable capacity over 50 cycles.
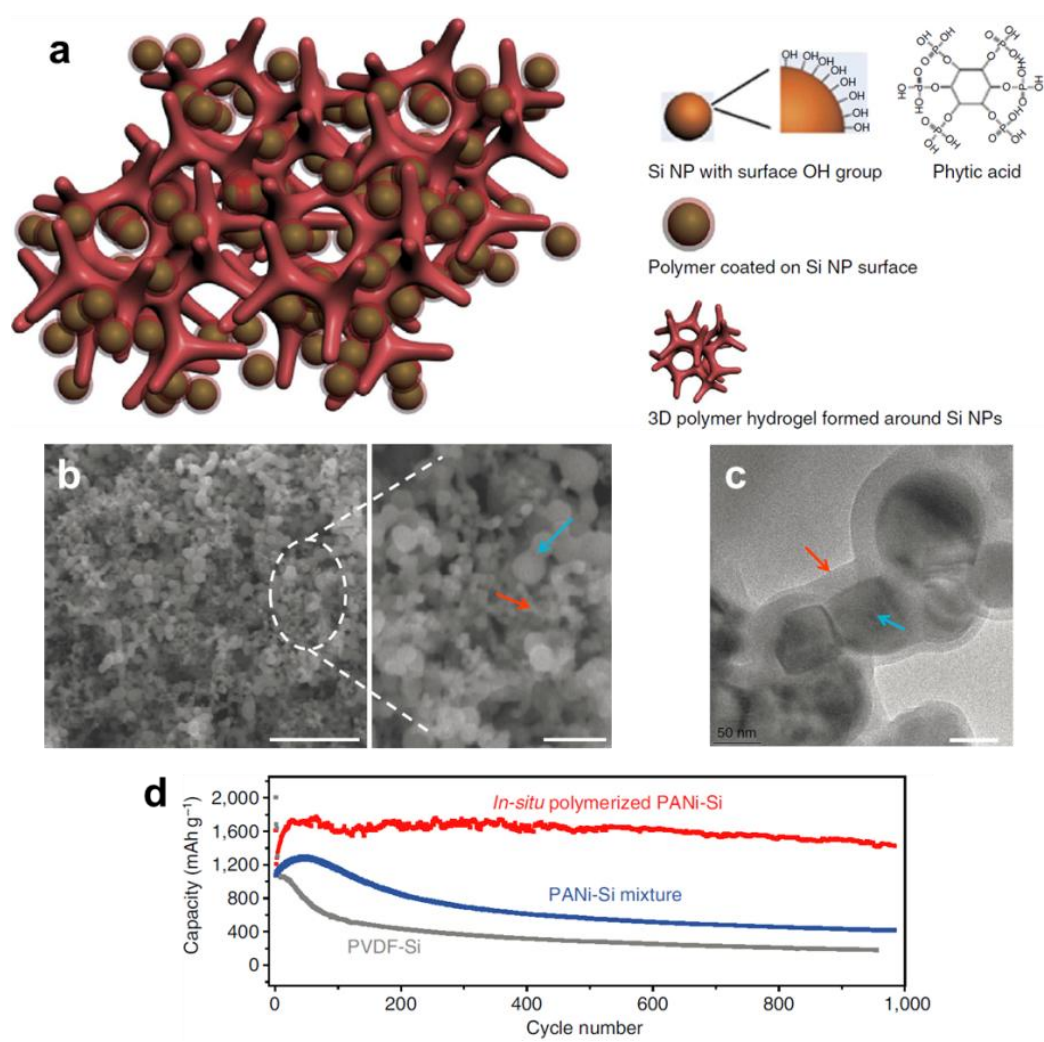

Figure 9. (a) Schematic description of the 3D porous $\mathrm{Si}$ nanoparticle/conductive polymer hydrogel composite electrodes. The silicon nanoparticles have been uniformly coated with a polymer layer. The interaction between $\mathrm{Si}$ nanoparticle and polymer is either between surface - $\mathrm{OH}$ groups and the phosphonic acids in the phytic acid crosslinker 
(right column), or the electrostatic interaction between negatively charged - $\mathrm{OH}$ groups and positively charged polyaniline due to phytic acid doping. (b) SEM image of a Si nanoparticle/polyaniline composite electrode at low (left) and high (right) magnifications. Scale bars are $1 \mu \mathrm{m}$ (left) and $200 \mathrm{~nm}$ (right). (c) TEM image indicating the conformal coating of polyaniline layer on Si nanoparticles. (d) Galvanostatic cycling performance of the in situ polymerized Si nanoparticle/polyaniline composite electrodes with a current density of $1.0 \mathrm{~A} / \mathrm{g}$. The two control samples are $\mathrm{Si}$ nanoparticle/polyaniline without in situ polymerization and a Si nanoparticle/PVDF electrode. Copyright 2013, Macmillan Publishers Ltd.

$\mathrm{Wu}$ et al. introduced a conducting polymer hydrogel frame work for Si nanoparticles via in situ polymerization of aniline in the slurry preparation process. An aniline monomer was well-mixed with Si nanoparticles, and an oxidizer was then added to trigger the polymerization. The fabricated electrode laminate exhibited a reversible capacity of above $500 \mathrm{mAh} / \mathrm{g}$ at $\sim 1.5 \mathrm{C}$ for over $5000 \mathrm{cycles}$, with an areal capacity of $\sim 0.7 \mathrm{mAh} / \mathrm{cm}^{2}[17]$. Besides the conductive nature of this in situ formed polymer hydrogel, several other improvements contributed to the electrochemical stability of this $\mathrm{Si}$ composite electrode. First, the mixing process used low-viscosity aniline monomer, the following in situ polymerization allows a conformal coating of the polymer onto Si nanoparticles; second, volume shrinkage was accompanied with this in situ process and the resulting porosity was supposed to help accommodate the volume expansion of Si particles; third, although pulverization of the large particles still occur during cell cycling, it is proposed that the conformal coating enabled good electrical connectivity among fractured particles (Figure 9a). An interesting observation was that the uniform conductive polymer coating enabled a deformable and stable SEI on the Si nanoparticles (Figure 9b and c). The positive results using in situ polymerization of conductive monomers have spurred followup work using other polymer structures such as pyrrole, combined with single-wall carbon nanotubes[84]; this design enabled a reversible delithiation capacity over $1600 \mathrm{mAh} / \mathrm{g}$ and $86 \%$ capacity retention after 1000 cycles at the current rate of $3.3 \mathrm{~A} / \mathrm{g}$, with an areal capacity of $0.4 \sim 0.7$ $\mathrm{mAh} / \mathrm{cm}^{2}$ (Figure 9d). Kummer et al. assembled nano-Si/polyaniline (PAN) nanocomposites as anode material[85], in which the nano-Si (with a mean crystallite size of $40 \mathrm{~nm}$ ) was embedded into the PAN matrix.

Compared to the polyaniline and polypyrrole used in the previous work, poly $(3,4-$ 
ethylenedioxythiophene) (PEDOT) has a higher electronic conductivity (10 1000 S/cm), which is a better choice for electrode applications[86], A precursor water solution containing poly(3,4ethylenedioxythiophene) doped with poly(4-styrenesulfonate) (PEDOT:PSS), super long (diameters of $30-80 \mathrm{~nm}$ and length of up to $1 \mathrm{~mm}$ ) carbon nanotube (CNT), and silicon nanoparticles was gelated by addition of gelation agents (ammonium persulfate), which promoted the formation of a hydrogel $\mathrm{Si}$ electrode. Several advantages of this design were discussed: the long CNT could ensure the mechanical robustness and long-range conductivity of the composite electrode; PEDOT:PSS is a conductive polymer with decent electronic conductivity, and a four-point probe shows a conductivity of $\sim 215 \mathrm{~S} / \mathrm{cm}$; and a PSS chain could cover the CNT surface, and the hydrophilic structure could interact with water, which facilitates the dispersion of CNT in water. A similar mechanism could also enable a good dispersion of the Si nanoparticles in the composite electrode. This combinatorial design enabled an impressive areal capacity of $2.2 \mathrm{mAh} / \mathrm{cm}^{2}$ in the initial cycle and above $1.8 \mathrm{mAh} / \mathrm{cm}^{2}$ after 100 cycles at a $\mathrm{C} / 10$ rate.

\subsection{Other novel binders designed for a $\mathrm{Si}$ anode}

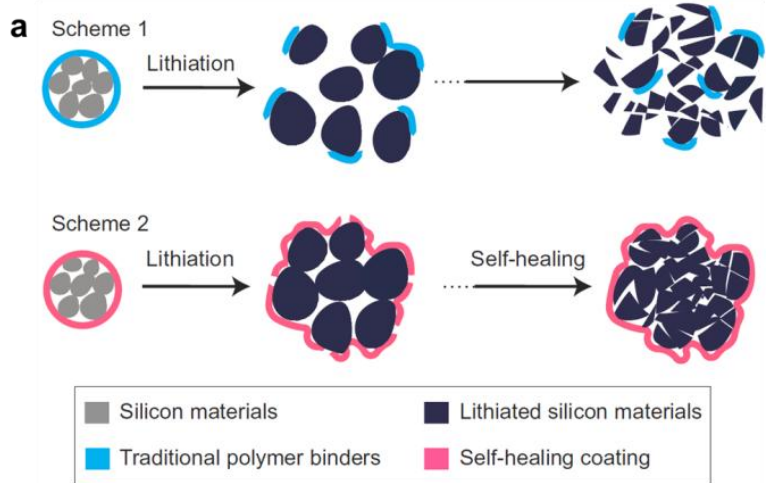

b
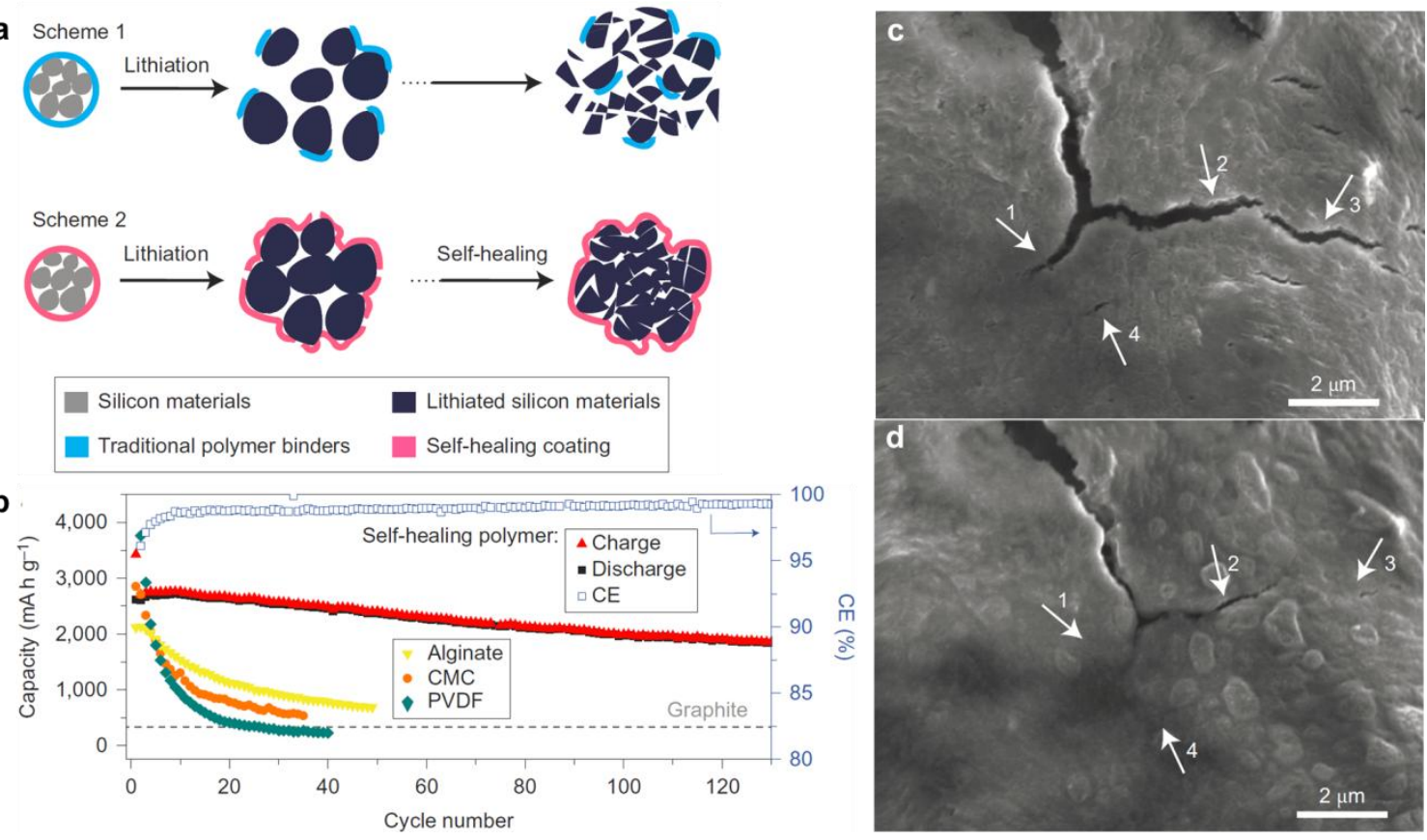

Figure 10. (a) Scheme 1: describes how particle cracking occurs using a conventional polymer binder, which leads to loss of electronic contact. Scheme 2: describes how the stretchable self-healing electrode maintains the electronic contact between cracked particles. (b) Galvanostatic cycling performance of Si microparticle electrodes with different 
polymer binders, including the self-healing polymer and the conventional PVDF, CMC and alginate polymers. (c) Cracks in the polymer layer in the lithiated state. (d) Healed cracks after five hours, indicated by the arrows on the images. Copyright 2013, Macmillan Publishers Ltd.

All the binder designs summarized in the previous sections aim to avoid Si electrode failure during cell cycling, and most of the previous work utilized Si nanoparticles as active materials. However, the wide application of Si nanoparticles is limited since it is only available in small quantities. Silicon microparticles (SiMPs) serve as a promising alternative[87], SiMPs are non-hazardous, cheap, and readily commercially available. Also the high tap-density of the micron-size particles facilitates the increase of the energy density of $\mathrm{Si}$ electrodes. However, compared to the nanoparticles, microparticles have even more serious structural changes, and the stress generated by the huge volumetric changes during the lithiation/delithiation of SiMPs induces fracture in the particles and polymer layers. This leads to the loss of electrical contact and causes extremely short cycling life over deep galvanostatic cycling[56, 88]. Wang et al. synthesized a hydrogen-bonding-directed self-healing polymer via a step-growth polymerization between Empol 1016 (a mixture of diacids and triacids) and diethylenetriamine $[89,90]$. Both low $T_{\mathrm{g}}\left(\sim 0{ }^{\circ} \mathrm{C}\right)$ and the hydrogen bonding in the polymer structure contributed to a self-healing property. It is proposed that the self-healing nature of this material enables the healing of cracks and damage in the laminate coating during cycling (Figure 10a, c, d). The self-healing polymer binder enables the SiMPs $(3 \sim 8 \mu \mathrm{m})$ to show a reversible capacity of 2600 $\mathrm{mAh} / \mathrm{g}-\mathrm{Si}$ at a $\mathrm{C} / 10$ rate for about 20 cycles. The mass loading of silicon was $0.5 \sim 0.7 \mathrm{mg} / \mathrm{cm}^{2}$, leading to an areal capacity of $1.5 \sim 2.1 \mathrm{mAh} / \mathrm{cm}^{2}$ (Figure 10b), an obvious increase of loading compared to many other previous reports using Si nanostructures[91]. Enabled by this self-healing polymer binder and the use of SiMPs, a high-areal capacity Si electrode was achieved recently at $\sim 2.5 \mathrm{mAh} / \mathrm{cm}^{2}$ with a current density of $0.3 \mathrm{~mA} / \mathrm{cm}^{2}[92]$.

Based on a variety of previous research, to identify the most critical property of the binder for $\mathrm{Si}$ anodes, systematic design of binders on the molecular level was performed for silicon anodes[93]. In the design of the multi-purpose polymer, 5-methyl-5-(4-vinylbenzyl), Meldrum's acid is used as a ketene precursor for crosslinking and initial covalent bonding to Si, styrene for stiffness, and methyl 
methacrylate for flexibility[94]. In addition, 2-methyl-2-(4-vinylbenzyl) malonate, which is a hydrolysis product of the Meldrum's acid, is used for self-healing effect via ion-dipole interactions between polymers and the native silanol groups on Si surface. By varying the ratio of these different monomers, important binder parameters such as crosslinking, initial covalent attachment, stiffness, flexibility, and self-healing are investigated. It is shown that crosslinking and initial covalent bonding lead to increased capacity, while self-healing is critical for high capacity value and stable cycling performance.

The performance of a lithium-ion cell relies on the concerted interaction of every single component in the cell, which includes active materials such as cathode and anode, as well as inactive materials such as binder, electrolyte, separator, etc. Table 1 is a non-exclusive list of polymer structures that have been explored as binders for high-capacity alloy-anodes in the literature.






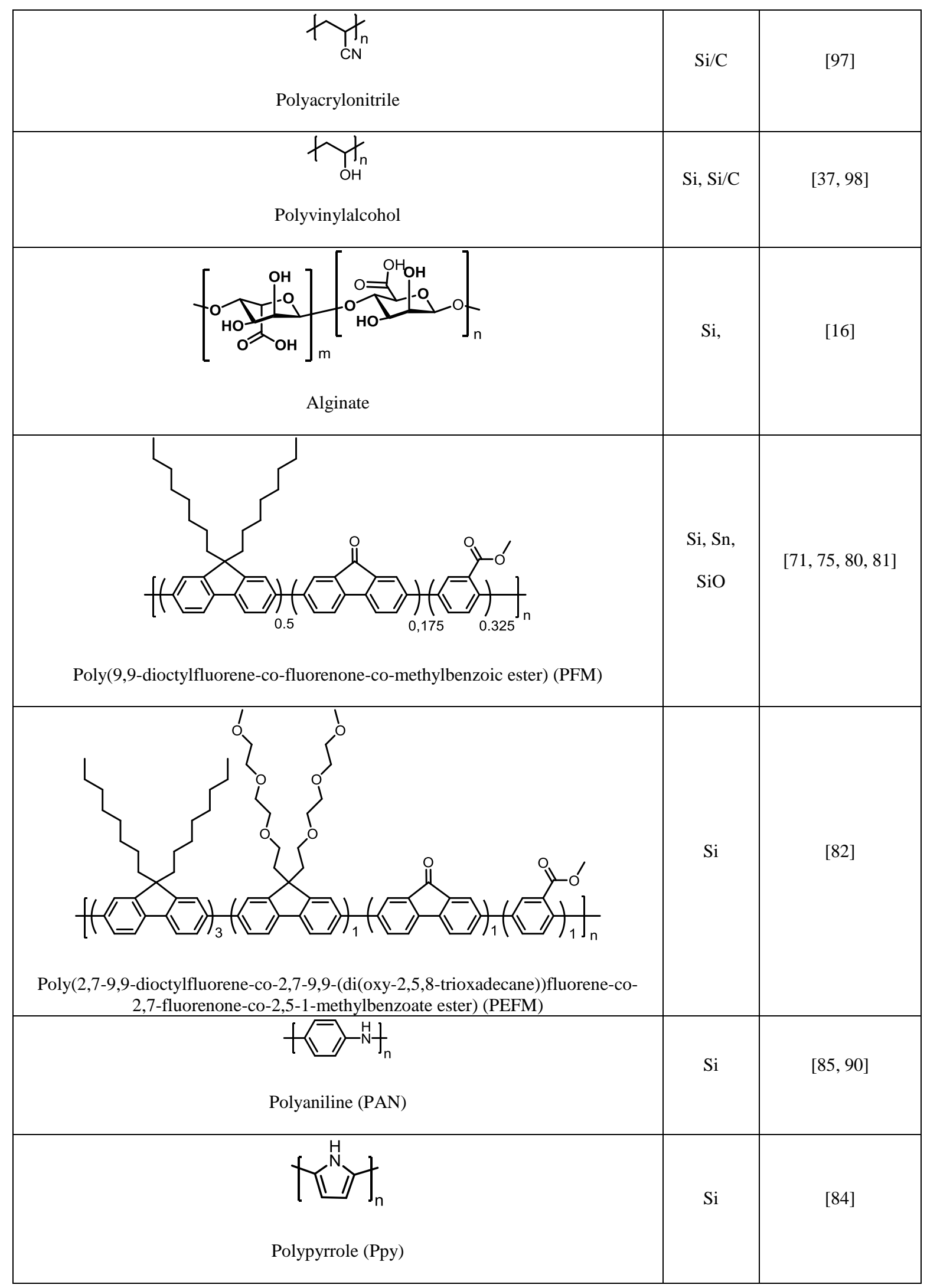


Table 1. A summary of the polymer binders developed for alloy anodes of LIBs.

\section{Issues of concern}




\subsection{The influence of electrolytes}

Although we cannot emphasize enough the importance of polymer binders in establishing stable cycling performance of high-capacity alloy anodes, the function of the polymer binder has to be considered in the whole lithium-ion cell, meaning that other aspects of the cell, such as the role of the electrolytes, also must be taken into account.[101, 102] Electrolyte additives were shown to be an effective and economic way of stabilizing SEI in LIBs[103]. Most of the work summarized in this review unanimously adopted FEC-containing electrolytes, varying from $2 \mathrm{wt} \%$ to $30 \mathrm{wt} \%$. FEC is regarded as an effective electrolyte additive to form a stable SEI on Si or Sn anode. The exact role of FEC, as well as the structure of SEI formed by FEC, is a controversial and hot topic in the field[104106].

\subsection{The influence of surface oxide layer on Si particles}

A native oxide layer terminated with a hydroxyl group always exists in commercially available silicon materials. It is readily formed during synthesis, storage, and transportation due to the presence of trace amounts of oxygen and water. Most of the current studies on the $\mathrm{Si}$ anode employ $\mathrm{Si}$ nanomaterials, including spherical particles, wires, or sponge structures, which tend to have enhanced surface area compared to the conventional micron-size graphite particles.[37] Still under intensive investigation is to what extent or under what conditions the SiOx species can be electrochemically reduced by lithium. Most of the reports show that the reduction products of this SiOx layer include $\mathrm{Li}_{2} \mathrm{O},[107,108]$ and different forms of silicates such as $\mathrm{Li}_{4} \mathrm{SiO}_{4}[107,109-112], \mathrm{Li}_{2} \mathrm{Si}_{2} \mathrm{O}_{5}[110,111]$, $\mathrm{Li}_{2} \mathrm{SiO}_{3}[112]$, etc. This surface $\mathrm{SiO}_{2}$ layer was shown to contribute to a higher first-cycle capacity loss compared to that of the Si samples etched by hydrofluoric acid[24, 113]. However, from the binder point of view, existing functional groups on the Si surface provide a reaction point with the polymer binders. This has been regarded as the origin of some useful binders, such as PAA, CMC, and alginate, for Si-based anodes.

\subsection{Characterization of the mechanical property of binders and electrodes}

The criteria of a good binder for a high-capacity alloy-anode lie on the improvement of electrochemical performance, i.e., cycling stability and CE. A good adhesion property, including 
particle/particle cohesion and laminate/Cu adhesion, also is an important prerequisite for a good binder. The mechanical property of a binder also affects the battery manufacturing; cell manufacturing processes such as winding and calendering could potentially unbind particles and/or lead to electrode delamination from the current collector. A delaminated electrode results in the loss of active materials; detached particles such as active material particles and a conductive additive may penetrate the separator during winding and cause the cell to short[114].

A peel test is normally used to analyze the adhesion strength provided by polymer binders in LIB electrodes $[15,82,115,116]$. In this test, adhesive tape is stuck onto the surface of an electrode. A high-precision micromechanical test system measures the peel strength while pulling the adhesive tape off the electrode. However, this method is highly dependent on the test conditions, such as the initial adhesion between the tape and the electrode surface, the type of the adhesive tapes, etc. In addition, the peel test results only reflect the adhesion property between the tape and the electrode surface, rather than the cohesion between particle/particle and adhesion between the electrode laminate and the current collector. Thus, to understand the mechanical property of the binder and electrode from a fundamental point of view, some other characterization techniques were developed.

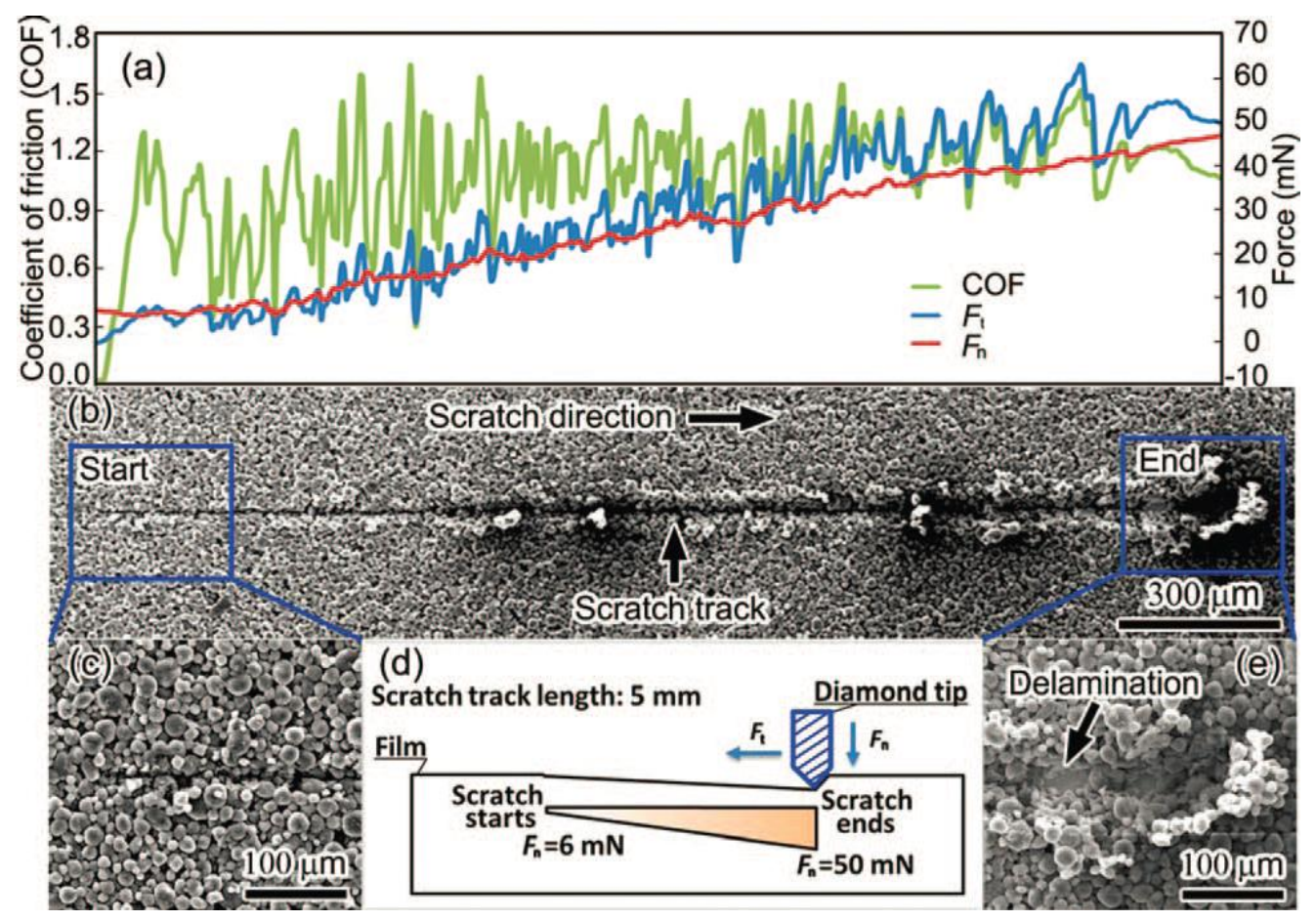

Figure 11. (a) Normal force $F_{n}$, tangential force $F_{t}$, and coefficient of friction curve of a MCMB/PVDF composite 
electrode as a function of scratching distance. (b) SEM image of the scratch track. (c) and (e) SEM images of the beginning and the end of the scratch track. (d) Schematic description of the scratch test. Copyright 2013, The Electrochemical Society.

A microscratch test was developed[117] employing a conical diamond stylus with a tip radium of $1.5 \mu \mathrm{m}$ and a cone angle of $60^{\circ}$. The scratch tip approached the film surface, and a $2 \mathrm{~mm}$ long scratch track was made by translating the sample while linearly ramping up the normal load on the conical tip. The tangential force $F_{n}$ and normal force $F_{t}$ were measured in real time (Figure 11a). The particle/particle cohesion strength was semi-qualitatively evaluated by analyzing the coefficient of friction $(\mathrm{COF})$, which can be readily calculated by $F_{n} / F_{t}$. Figure 11 shows the schematic illustration of the scratch test, as well as the scratch tack and measured tangential and normal forces.

\section{Concluding remarks and outlook}

Recent work on the binder development establishes the binder as a key component to enable the application of high-capacity alloy-anodes, such as silicon and tin in LIBs. Take silicon as an example: specific capacities of $2000 \mathrm{mAh} / \mathrm{g}$ at low rate $(0.1 \mathrm{C})$ or $1500 \mathrm{mAh} / \mathrm{g}$ at a high rate $(0.5 \mathrm{C} \sim 1 \mathrm{C})$ for longterm cycling (over 500 cycles) are now well achieved. Still many issues remain to be solved before producing a commercial application of alloy anodes:

1. Most of the work on silicon anodes, including the development of new binders and modification of silicon active material, focuses on high value and stable specific capacity. However, as shown by Dahn et al.[118], specific capacity may not be so indicative of the ultimate performance of an electrode's active materials. The loading of the silicon per area is still quite small in most of the current work, with an areal capacity of typically less than 0.5 $\mathrm{mAh} / \mathrm{cm}^{2}$. This does not gain much advantage compared to the state-of-the-art graphite anodes, which could easily attain an areal capacity of $\sim 3 \mathrm{mAh} / \mathrm{cm}^{2}$. Several recent publications show that scientists in this field already are devising different solutions for this problem[75, 119], so it is expected that more attention will be drawn toward a high-loading silicon electrode.

2. Relevant to the above issue, several of the high areal-capacity Si anodes in literature rely on 
creating high porosities to accommodate the large volume changes during cycling $[75,119]$, which sacrificed the electrode density and volumetric capacity. Only low electrode densities at $0.6 \sim 0.8 \mathrm{~g} / \mathrm{cm}^{3}$ were obtained in those high-porosity electrodes, compared to $1.2 \sim 1.6 \mathrm{~g} / \mathrm{cm}^{3}$ for the graphite electrode. In many other literatures, there are even not enough data disclosed to estimate the density of the reported $\mathrm{Si}$ electrode. To be of any practical value, $\mathrm{Si}$ anode with comparable electrode densities with graphite should be pursued, several of recent papers made considerable progress toward high-density $\mathrm{Si}$ anode with stable cycling performance[77, 120].

3. The conventional PVDF binder works well for different types of graphite anodes and cathode material; however, this is not the case for the alloy-anodes. Alloy-anode materials generated from different production processes, varying at different particle sizes, tap densities, surface chemistries, and specific capacities (volume changes) typically prefer a specific binder over another. This explains some of the data discrepancy from different research groups. For example, in one publication, alginate enables the best performance of a Si anode[16], while another work, although employing the same electrode composition and testing procedure, shows that PAA gives the best performance[37]. The former work used Si nanoparticles from MTI Corporation, and the latter obtained its Si from Alfa Aesar. The different sources of Si active materials might explain the different performances using different binders. This "specific binder for a specific active material" rule indicates our paucity of understanding on the role of binders for alloy anodes in LIBs. Although many important pieces of the jigsaw puzzle that enlightens us about the interaction of polymer binders and anode active particles have been discovered, they do not quite connect.

4. Most of the work on binders for Si anodes, or even the research on alloy-anodes as a whole, focuses on the half-cell study with lithium metal as a counter electrode. The use of the $\mathrm{Si}$ anode has to be considered in a real lithium-ion full cell. Several questions need to be answered: if a stable cycling performance could be achieved in a lithium-ion full battery, is there any gain on energy density by incorporating Si into LIBs? Should we use pure $\mathrm{Si}$ or $\mathrm{Sn}$ 
as anodes, or would it be better choice to use a mixture of graphite/alloy anodes? Some of the recent work shows that people are already seriously considering these questions. Obrovac and co-workers investigated the effect of calendering and mixing graphite to composite electrodes comprising Si alloy particles[120]. Their systematic study indicates that only when alloys are blended with graphite and calendered to high densities, can the best cycle life, the highest energy density, and the lowest volume expansion electrodes be obtained. It is believed that this is the most likely way the high-capacity alloys could be utilized in commercial cells. Current prismatic and cylindrical cells can only withstand $<30 \%$ volume expansion of the electrode considering $\sim 16 \%$ expansion of the graphite. Thus, the mixed Si should not be in large portion without careful electrode engineering to minimize the electrode-level volume expansion.

Regardless of the existing challenges, significant progress has been made on the development of polymer binders as a key electrode component to enable the application of high-capacity alloy anodes for a hierarchical electrode design of Si and Sn nanomaterials for LIBs.

\section{Acknowledgements}

This work is funded by the Assistant Secretary for Energy Efficiency, Vehicle Technologies Office of the U.S. Department of Energy, under the Exploratory Battery Materials Research (BMR) and Applied Battery Research (ABR) Programs under contract no. DE-AC02-05CH11231.

\section{References}

[1] J.B. Goodenough, K.-S. Park, J. Am. Chem. Soc., 135 (2013) 1167-1176.

[2] M. Ebner, F. Geldmacher, F. Marone, M. Stampanoni, V. Wood, Adv. Energy Mater., 3 (2013) 845850.

[3] M. Ebner, F. Marone, M. Stampanoni, V. Wood, Science, 342 (2013) 716-720.

[4] M. Ebner, D.-W. Chung, R.E. García, V. Wood, Adv. Energy Mater., 4 (2014) 1301278.

[5] R. Fong, U. von Sacken, J.R. Dahn, J. Electrochem. Soc., 137 (1990) 2009-2013.

[6] S.W. Lee, M.T. McDowell, L.A. Berla, W.D. Nix, Y. Cui, Pro. Natl. Acad. Sci., 109 (2012) 40804085.

[7] P.G. Bruce, B. Scrosati, J.-M. Tarascon, Angew. Chem. In. Ed., 47 (2008) 2930-2946.

[8] C.K. Chan, H. Peng, G. Liu, K. Mcllwrath, X.F. Zhang, R.A. Huggins, et al., Nat. Nanotechnol., 3 (2008) 31-35.

[9] R. Deshpande, Y.-T. Cheng, M.W. Verbrugge, J. Power Sources, 195 (2010) 5081-5088.

[10] M.-H. Park, M.G. Kim, J. Joo, K. Kim, J. Kim, S. Ahn, et al., Nano Lett., 9 (2009) 3844-3847. 
[11] J.-K. Yoo, J. Kim, Y.S. Jung, K. Kang, Adv. Mater., 24 (2012) 5452-5456.

[12] Y. He, X. Yu, Y. Wang, H. Li, X. Huang, Adv. Mater., 23 (2011) 4938-4941.

[13] H. Wu, Y. Cui, Nano Today, 7 (2012) 414-429.

[14] F. Shi, H. Zhao, G. Liu, P.N. Ross, G.A. Somorjai, K. Komvopoulos, J. Phys. Chem. C, 118 (2014) 14732-14738.

[15] C.-M. Park, J.-H. Kim, H. Kim, H.-J. Sohn, Chem. Soc. Rev., 39 (2010) 3115-3141.

[16] I. Kovalenko, B. Zdyrko, A. Magasinski, B. Hertzberg, Z. Milicev, R. Burtovyy, et al., Science, 334 (2011) 75-79.

[17] H. Wu, G. Yu, L. Pan, N. Liu, M.T. McDowell, Z. Bao, et al., Nat. Comm., 4 (2013) 6.

[18] J. Comyn, Adhesion Science, The Royal Society of Chemistry, Thomas Graham House, Science Park, Milton Road, Cambridge CB4 4WF, UK 1997.

[19] G. Liu, H. Zheng, A.S. Simens, A.M. Minor, X. Song, V.S. Battaglia, J. Electrochem. Soc., 154 (2007) A1129-A1134.

[20] G. Liu, H. Zheng, S. Kim, Y. Deng, A.M. Minor, X. Song, et al., J. Electrochem. Soc., 155 (2008) A887-A892.

[21] D. Guy, B. Lestriez, R. Bouchet, V. Gaudefroy, D. Guyomard, Electrochem. Solid-State Lett., 8 (2005) A17-A21.

[22] D. Guy, B. Lestriez, R. Bouchet, D. Guyomard, J. Electrochem. Soc., 153 (2006) A679-A688.

[23] G. Liu, H. Zheng, X. Song, V.S. Battaglia, J. Electrochem. Soc., 159 (2012) A214-A221.

[24] S. Xun, X. Song, L. Wang, M.E. Grass, Z. Liu, V.S. Battaglia, et al., J. Electrochem. Soc., 158 (2011) A1260-A1266.

[25] X. Su, Q. Wu, J. Li, X. Xiao, A. Lott, W. Lu, et al., Adv. Energy Mater., 4 (2013) 1300882.

[26] K.-Q. Peng, X. Wang, L. Li, Y. Hu, S.-T. Lee, Nano Today, 8 (2013) 75-97.

[27] Y. Xu, Q. Liu, Y. Zhu, Y. Liu, A. Langrock, M.R. Zachariah, et al., Nano Lett., 13 (2013) 470-474.

[28] E. Tsuchida, H. Ohno, K. Tsunemi, Electrochim. Acta, 28 (1983) 591-595.

[29] A. Kurihara, A. Nagai, The 39th Battery Symposium in Japan1998, pp. 309.

[30] L.Y. Beaulieu, K.W. Eberman, R.L. Turner, L.J. Krause, J.R. Dahn, Electrochem. Solid-State Lett., 4 (2001) A137-A140.

[31] J. Li, L. Christensen, M.N. Obrovac, K.C. Hewitt, J.R. Dahn, J. Electrochem. Soc., 155 (2008) A234-A238.

[32] Z. Chen, L. Christensen, J.R. Dahn, J. Appl. Polym. Sci., 90 (2003) 1891-1899.

[33] Z. Chen, L. Christensen, J.R. Dahn, J. Electrochem. Soc., 150 (2003) A1073-A1078.

[34] Z. Chen, L. Christensen, J.R. Dahn, J. Appl. Polym. Sci., 91 (2004) 2958-2965.

[35] R.R. Garsuch, D.-B. Le, A. Garsuch, J. Li, S. Wang, A. Farooq, J.R. Dahn, J. Electrochem. Soc., 155 (2008) A721-A724.

[36] A. Magasinski, B. Zdyrko, I. Kovalenko, B. Hertzberg, R. Burtovyy, C.F. Huebner, et al., ACS Appl. Mater. \& Interfaces, 2 (2010) 3004-3010.

[37] C. Erk, T. Brezesinski, H. Sommer, R. Schneider, J. Janek, ACS Appl. Mater. \& Interfaces, 5 (2013) 7299-7307.

[38] N. Yabuuchi, K. Shimomura, Y. Shimbe, T. Ozeki, J.-Y. Son, H. Oji, et al., Adv. Energy Mater., 1 (2011) 759-765.

[39] S. Komaba, N. Yabuuchi, T. Ozeki, Z.-J. Han, K. Shimomura, H. Yui, et al., J. Phys. Chem. C, 116 (2011) 1380-1389.

[40] Z.-J. Han, N. Yabuuchi, K. Shimomura, M. Murase, H. Yui, S. Komaba, Energy Environ. Sci., 5 (2012) 9014-9020.

[41] Z.-J. Han, N. Yabuuchi, S. Hashimoto, T. Sasaki, S. Komaba, ECS Electrochem. Lett., 2 (2013) A17-A20.

[42] S. Komaba, K. Shimomura, N. Yabuuchi, T. Ozeki, H. Yui, K. Konno, J. Phys. Chem. C, 115 (2011) 13487-13495.

[43] J. Li, D.-B. Le, P.P. Ferguson, J.R. Dahn, Electrochim. Acta, 55 (2010) 2991-2995.

[44] M. Masiak, W. Hyk, Z. Stojek, M. Ciszkowska, J. Phys. Chem. B, 111 (2007) 11194-11200.

[45] J. Song, M. Zhou, R. Yi, T. Xu, M.L. Gordin, D. Tang, et al., Adv. Funct. Mater., 24 (2014) 59045910. 
[46] M. Ling, J. Qiu, S. Li, H. Zhao, G. Liu, S. Zhang, J. Mater. Chem. A, 1 (2013) 11543-11547.

[47] M. Murase, N. Yabuuchi, Z.-J. Han, J.-Y. Son, Y.-T. Cui, H. Oji, et al., ChemSusChem, 5 (2012) 2307-2311.

[48] C. Kim, J.Y. Jang, N.-S. Choi, S. Park, RSC Adv., 4 (2014) 3070-3074.

[49] M. Ling, Y. Xu, H. Zhao, X. Gu, J. Qiu, S. Li, et al., Nano Energy, 12 (2015) 178-185.

[50] Polymer Handbook, 3rd ed., John Wiley and Sons, New York, 1989.

[51] Lithium Ion Batteries: Science and Technology, Springer Science + Business Media, LLC2009.

[52] W.-R. Liu, M.-H. Yang, H.-C. Wu, S.M. Chiao, N.-L. Wu, Electrochem. Solid-State Lett., 8 (2005) A100-A103.

[53] H. Buqa, M. Holzapfel, F. Krumeich, C. Veit, P. Novák, J. Power Sources, 161 (2006) 617-622.

[54] J. Li, R.B. Lewis, J.R. Dahn, Electrochem. Solid-State Lett., 10 (2007) A17-A20.

[55] B. Key, R. Bhattacharyya, M. Morcrette, V. Seznéc, J.-M. Tarascon, C.P. Grey, J. Am. Chem.

Soc., 131 (2009) 9239-9249.

[56] J. Guo, C. Wang, Chem. Comm., 46 (2010) 1428-1430.

[57] N.S. Hochgatterer, M.R. Schweiger, S. Koller, P.R. Raimann, T. Wöhrle, C. Wurm, et al., Electrochem. Solid-State Lett., 11 (2008) A76-A80.

[58] J.S. Bridel, T. Azaïs, M. Morcrette, J.M. Tarascon, D. Larcher, Chem. Mater., 22 (2009) 12291241.

[59] D. Mazouzi, B. Lestriez, L. Roué, D. Guyomard, Electrochem. Solid-State Lett., 12 (2009) A215A218.

[60] B. Lestriez, S. Bahri, I. Sandu, L. Roué, D. Guyomard, Electrochem. Comm., 9 (2007) 28012806.

[61] L. El Ouatani, R. Dedryvère, J.B. Ledeuil, C. Siret, P. Biensan, J. Desbrières, et al., J. Power Sources, 189 (2009) 72-80.

[62] L. Yue, L. Zhang, H. Zhong, J. Power Sources, 247 (2014) 327-331.

[63] B. Koo, H. Kim, Y. Cho, K.T. Lee, N.-S. Choi, J. Cho, Angew. Chem. Int. Ed., 51 (2012) 87628767.

[64] M. Ling, H. Zhao, X. Xiaoc, F. Shi, M. Wu, J. Qiu, et al., J. Mater. Chem. A, 3 (2015) 2036-2042.

[65] H. Lee, N.F. Scherer, P.B. Messersmith, Proc. Natl. Acad. Sci., 103 (2006) 12999-13003.

[66] H. Lee, B.P. Lee, P.B. Messersmith, Nature 448 (2007) 338-341.

[67] M.-H. Ryou, J. Kim, I. Lee, S. Kim, Y.K. Jeong, S. Hong, et al., Adv. Mater., 25 (2013) 15711576.

[68] Y. Park, S. Lee, S.-H. Kim, B.Y. Jang, J.S. Kim, S.M. Oh, et al., RSC Adv., 3 (2013) 1262512630.

[69] Y.K. Jeong, T.-w. Kwon, I. Lee, T.-S. Kim, A. Coskun, J.W. Choi, Nano Lett., 14 (2014) 864-870.

[70] J.L. Bredas, G.B. Street, Acc. Chem. Res., 18 (1985) 309-315.

[71] G. Liu, S. Xun, N. Vukmirovic, X. Song, P. Olalde-Velasco, H. Zheng, et al., Adv. Mater., 23 (2011) 4679-4683.

[72] Y. Deng, W. Yuan, Z. Jia, G. Liu, J. Phys. Chem. B, 118 (2014) 14536-14545.

[73] J. Saint, M. Morcrette, D. Larcher, L. Laffont, S. Beattie, J.P. Pérès, et al., Adv. Funct.l Mater., 17 (2007) 1765-1774.

[74] S.D. Beattie, D. Larcher, M. Morcrette, B. Simon, J.-M. Tarascon, J. Electrochem. Soc., 155 (2008) A158-A163.

[75] S. Xun, B. Xiang, A. Minor, V. Battaglia, G. Liu, J. Electrochem. Soc., 160 (2013) A1380-A1383.

[76] M. Wu, J.E.C. Sabisch, X. Song, A.M. Minor, V.S. Battaglia, G. Liu, Nano Lett., 13 (2013) 53975402.

[77] H. Zhao, N. Yuca, Z. Zheng, Y. Fu, V.S. Battaglia, G. Abdelbast, et al., ACS Appl. Mater. \& Interfaces, 7 (2015) 862-866.

[78] Z. Wang, Y. Fu, Z. Zhang, S. Yuan, K. Amine, V. Battaglia, et al., J. Power Sources, 260 (2014) 57-61.

[79] J.T. Vaughey, G. Liu, J.-G. Zhang, MRS Bull., 39 (2014) 429-435.

[80] S. Xun, X. Song, V. Battaglia, G. Liu, J. Electrochem. Soc., 160 (2013) A849-A855.

[81] K. Dai, H. Zhao, Z. Wang, X. Song, V. Battaglia, G. Liu, J. Power Sources, 263 (2014) 276-279. 
[82] M. Wu, X. Xiao, N. Vukmirovic, S. Xun, P.K. Das, X. Song, et al., J. Am. Chem. Soc., 135 (2013) 12048-12056.

[83] M. Wu, X. Song, X. Liu, V. Battaglia, W. Yang, G. Liu, J. Mater. Chem. A, (2015) DOI: 10.1039/C1034TA06594H.

[84] B. Liu, P. Soares, C. Checkles, Y. Zhao, G. Yu, Nano Lett., 13 (2013) 3414-3419.

[85] M. Kummer, J.P. Badillo, A. Schmitz, H.-G. Bremes, M. Winter, C. Schulz, et al., J. Electrochem. Soc., 161 (2014) A40-A45.

[86] Z. Chen, J.W.F. To, C. Wang, Z. Lu, N. Liu, A. Chortos, et al., Adv. Energy Mater., 4 (2014) 1400207.

[87] U. Kasavajjula, C. Wang, A.J. Appleby, J. Power Sources, 163 (2007) 1003-1039.

[88] W.-R. Liu, Z.-Z. Guo, W.-S. Young, D.-T. Shieh, H.-C. Wu, M.-H. Yang, et al., J. Power Sources, 140 (2005) 139-144.

[89] B.C.-K. Tee, C. Wang, R. Allen, Z. Bao, Nat. Nanotechnol., 7 (2012) 825-832.

[90] C. Wang, H. Wu, Z. Chen, M.T. McDowell, Y. Cui, Z. Bao, Nat. Chem., 5 (2013) 1042-1048.

[91] C.K. Chan, H. Peng, G. Liu, K. McIlwrath, X.F. Zhang, R.A. Huggins, et al., Nat. Nanotechnol., 3 (2008) 31-35.

[92] Z. Chen, C. Wang, J. Lopez, Z. Lu, Y. Cui, Z. Bao, Adv. Energy Mater., (2015) DOI: 10.1002/aenm.201401826.

[93] T.-w. Kwon, Y.K. Jeong, I. Lee, T.-S. Kim, J.W. Choi, A. Coskun, Adv. Mater., 26 (2014) 79797985.

[94] N. Yuca, H. Zhao, X. Song, M.F. Dogdu, W. Yuan, Y. Fu, et al., ACS Appl. Mater. \& Interfaces, 6 (2014) 17111-17118.

[95] T. Yim, S.J. Choi, Y.N. Jo, T.-H. Kim, K.J. Kim, G. Jeong, et al., Electrochim. Acta, 136 112-120. [96] B. Liu, A. Abouimrane, Y. Ren, M. Balasubramanian, D. Wang, Z.Z. Fang, et al., Chem. Mater., 24 (2012) 4653-4661.

[97] L. Gong, M.H.T. Nguyen, E.-S. Oh, Electrochem. Commun., 29 (2013) 45-47.

[98] H.-K. Park, B.-S. Kong, E.-S. Oh, Electrochem. Commun., 13 (2011) 1051-1053.

[99] L. Yue, S. Wang, X. Zhao, L. Zhang, J. Mater. Chem., 22 (2012) 1094-1099.

[100] Y. Chen, S. Zeng, J. Qian, Y. Wang, Y. Cao, H. Yang, et al., ACS Appl. Mater. \& Interfaces, 6 (2014) 3508-3512.

[101] H. Zhao, X. Zhou, S.-J. Park, F. Shi, Y. Fu, M. Ling, et al., J. Power Sources, 263 (2014) 288295.

[102] H. Zhao, S.-J. Park, F. Shi, Y. Fu, V. Battaglia, P.N. Ross, et al., J. Electrochem. Soc., 161 (2014) A194-A200.

[103] S.S. Zhang, J. Power Sources, 162 (2006) 1379-1394.

[104] V. Etacheri, O. Haik, Y. Goffer, G.A. Roberts, I.C. Stefan, R. Fasching, et al., Langmuir, 28 (2011) 965-976.

[105] M. Nie, D.P. Abraham, Y. Chen, A. Bose, B.L. Lucht, J. Phys. Chem. C, 117 (2013) 1340313412.

[106] X. Chen, X. Li, D. Mei, J. Feng, M.Y. Hu, J. Hu, et al., ChemSusChem, 7 (2013) 549-554.

[107] J.-H. Kim, C.-M. Park, H. Kim, Y.-J. Kim, H.-J. Sohn, J. Electroanal. Chem., 661 (2011) 245249.

[108] B. Guo, J. Shu, Z. Wang, H. Yang, L. Shi, Y. Liu, et al., Electrochem. Commun., 10 (2008) 1876-1878.

[109] Y. Hwa, C.-M. Park, H.-J. Sohn, J.Power Sources, 222 (2013) 129-134.

[110] B.-C. Yu, Y. Hwa, C.-M. Park, H.-J. Sohn, J. Mater. Chem. A, 1 (2013) 4820-4825.

[111] W.-S. Chang, C.-M. Park, J.-H. Kim, Y.-U. Kim, G. Jeong, H.-J. Sohn, Energy Environ. Sci., 5 (2012) 6895-6899.

[112] M. Yamada, A. Inaba, A. Ueda, K. Matsumoto, T. Iwasaki, T. Ohzuku, J. Electrochem. Soc., 159 (2012) A1630-A1635.

[113] S. Xun, X. Song, M.E. Grass, D.K. Roseguo, Z. Liu, V.S. Battaglia, et al., Electrochem. SolidState Lett., 14 (2011) A61-A63.

[114] X. Huang, J. Solid State Electrochem., 15 (2011) 649-662. 
[115] L. Chen, X. Xie, J. Xie, K. Wang, J. Yang, J. Appl. Electrochem., 36 (2006) 1099-1104.

[116] J.-H. Lee, U. Paik, V.A. Hackley, Y.-M. Choi, J. Power Sources, 161 (2006) 612-616.

[117] J. Chen, J. Liu, Y. Qi, T. Sun, X. Li, J. Electrochem. Soc., 160 (2013) A1502-A1509.

[118] M.N. Obrovac, L. Christensen, D.B. Le, J.R. Dahn, J. Electrochem. Soc., 154 (2007) A849A855.

[119] N. Liu, Z. Lu, J. Zhao, M.T. McDowell, H.-W. Lee, W. Zhao, et al., Nat. Nanotechnol., 9 (2014) 187-192.

[120] Z. Du, R.A. Dunlap, M.N. Obrovac, J. Electrochem. Soc., 161 (2014) A1698-A1705.

\section{Graphic Abstract}


